\title{
Composição química de Eichhornia crassipes (Mart) Solms, no sistema de Baías Chacororé-Sinhá Mariana Pantanal de Mato Grosso, Brasil
}

\author{
Chemical composition of Eichhornia crassipes (Mart) Solms, in the Chacororé-Sinhá Mariana lake- \\ system Pantanal of Mato Grosso, Brazil \\ Composición química de Eichhornia crassipes (Mart) Solms, en el sistema de bahías Chacororé- \\ Sinhá Mariana Pantanal de Mato Grosso, Brasil
}

Recebido: 13/01/2022 | Revisado: 18/01/2022 | Aceito: 21/01/2022 | Publicado: 23/01/2022

\author{
Josué Ribeiro da Silva Nunes \\ ORCID: https://orcid.org/0000-0003-3927-5063 \\ Universidade do Estado de Mato Grosso, Brasil \\ E-mail: josue@unemat.br \\ Carolina Joana da Silva \\ ORCID: https://orcid.org/0000-0003-0517-1661 \\ Universidade do Estado de Mato Grosso, Brasil \\ E-mail: ecopanta@terra.br
}

\begin{abstract}
Resumo
O Pantanal constitui-se na maior planície alagável do mundo, englobando um mosaico de diferentes habitats, sustentando rica biota aquática e terrestre. Este mosaico de habitats do Pantanal é bem representado no município de Barão de Melgaço pelo sistema de baías Chacororé-Sinhá Mariana, este sistema de baías, lagoas parentais do rio Cuiabá são reconhecidas pela sua produtividade aquática e beleza cênica. As macrófitas aquáticas são organismos extremamente abundantes no Pantanal sendo considerada a comunidade mais produtiva dos sistemas alagáveis, com grande capacidade de acumulação de biomassa e nutrientes. As coletas foram realizadas em três pontos de coleta, Baía Chacororé, Baía Sinhá Mariana e a transição entre elas. Este estudo teve como objetivo analisar a variação temporal e espacial dos principais nutrientes na biomassa de E. crassipes no Sistema de Baías Chacororé-Sinhá Mariana. Os resultados mostraram que a baía de Chacororé apresentou maior concentração de fósforo total, de conteúdo mineral, sódio, cálcio e potássio das estações de coleta amostradas na estiagem, também apresentou maior concentração de Nitrogênio total, mas na cheia. A maior concetração de magnésio foi obtida na cheia e na estação de coleta SMM. Esta pesquisa corrobora outros estudos realizados no Pantanal sobre a importância do pulso de inundação na variação temporal da concentração de nutrientes na biomassa de E. crassipes nas baías e evidência a heterogeneidade espacial existente entre estas. Dessa forma as macrófitas aquáticas podem indicar os impactos resultantes das mudanças hidrológicas nesse sistema de baías.
\end{abstract}

Palavras-chave: Dinâmica temporal; Pulso de inundação; Macrófitas aquáticas; Heterogeneidade.

\begin{abstract}
The Pantanal constitutes the biggest floodplain of the world, forming a mosaic of different habitats, sustaining rich aquatic and terrestrial biota. This mosaic of habitats of the Pantanal is well represented in the Barão de Melgaço region by the Chacororé-Sinhá Mariana Lake System, this system of parental lakes of Cuiabá river are recognized by their aquatic productivity and scenically beauty. The aquatic macrophyte are very abundant organisms being considered the most productive community in the aquatic system, with great capacity of accumulate biomass and nutrients. The samples were collected into three stations representing the Chacororé-Sinhá Mariana lake system and the transition between them. This study had as purpose to evaluate the spatial and temporal of the main nutrients in the biomass in E. crassipes in the stands of this specie in Chacororé-Sinhá Mariana "baía" system. The results showed that chacororé bay presented higher concentration of total phosphorus, mineral content, sodium, calcium and potassium of the collection stations sampled in the drought, also presented higher concentration of total nitrogen, but in the flood. The highest magnesium design was obtained in the flood on SMM collection station. This research supports another studies realized in the Pantanal about the importance of the "flood pulse" in the temporal variation of the nutrients concentration in the biomass of E. crassipes and shown that the variation of the biomass of $E$. crassipes in the lakes evidence the spatial heterogeneity which exists between those lakes. In this way the aquatic macrophyte can indicate the impacts resulting of the hydrological changes in this system of lakes.
\end{abstract}

Keywords: Temporal dynamic; Flood pulse; Aquatic macrophyte; Heterogeneity. 


\begin{abstract}
Resumen
El Pantanal es la llanura de inundación más grande del mundo, abarcando un mosaico de diferentes hábitats, sosteniendo rica biota acuática y terrestre. Este mosaico de hábitats del Pantanal está bien representado en Barão de Melgaço por el sistema de Baías Chacororé-Sinhá Mariana, este sistema de baías de las lagunas parentales del río Cuiabá son reconocidos por su productividad acuática y belleza escénica. Los macrófitos acuáticos son organismos extremadamente abundantes en el Pantanal y son considerados la comunidad más productiva de sistemas inundados, con gran capacidad de biomasa y acumulación de nutrientes. Las colecciones se llevaron a cabo en tres estaciones que representan la Baía de Chacororé, la Baía de Sinhá Mariana y el punto de transición entre ellas. Este estudio tenía como objetivo evaluar la dinámica espacial y temporal de los nutrientes en la biomasa de E. crassipes en los stands de esta especie en el sistema de baía Chacororé-Sinhá Mariana. Los resultados mostraron que la bahía de chacororé presentó mayor concentración de fósforo total, contenido mineral, sodio, calcio y potasio de las estaciones de recolección muestreadas en la sequía, también presentó mayor concentración de nitrógeno total, pero en la inundación. El diseño de magnesio más alto se obtuvo en la estación de recolección completa y SMM. Esta investigación corrobora con otros estudios realizados en el Pantanal sobre la importancia del pulso de inundación en la variación temporal de los nutrientes de la biomasa y muestra que la variación de E. crassipes en las baías evidencia la heterogeneidad espacial existente entre ellas. Por lo tanto, los macrófitos acuáticos pueden indicar los impactos resultantes de los cambios hidrológicos en este sistema de baía.
\end{abstract}

Palabras clave: Dinámica temporal; Pulso de inundación; Macrofitos acuáticos; Heterogeneidad.

\title{
1. Introdução
}

Todos os vegetais necessitam de nutrientes para metabolizar os compostos essenciais para sua existência. Existem ao todo dezesseis nutrientes essenciais para as plantas, e estes estão divididos em macro e micro-nutrientes, baseado nas quantidades necessárias para as plantas, Cerca de $95 \%$ a 99,55\% do peso fresco da planta é constituído de carbono, oxigênio e hidrogênio, por outro lado magnésio representa cerca de $0,18 \%$ do peso de algumas espécies vegetais, além dos citados os macronutrientes são: nitrogênio, fósforo, cálcio, sódio e potássio. Os micro-nutrientes são, ferro, manganês, boro, zinco, cobre, molibdênio e cloro, os micro-nutrientes não são menos importantes que os macros eles só diferem na quantidade (Riemer 1984).

Embora não existam muitas informações quantitativas das necessidades de nutrientes das espécies de macrófitas aquáticas, não existe dúvida de que sua ocorrência e taxa de crescimento é muito influenciada pelo regime de nutrientes. (Junk \& Howard-Williams 1984). A matéria orgânica produzida pelos organismos produtores primários é processada por um grande número de espécies decompositoras que liberam para o ambiente uma grande quantidade de nutrientes prontos para ser assimilados (Furch \& Junk 1997). Eichhornia crassipes ocorre frequentemente em habitats com as mais diferentes concentrações de nutrientes, embora desenvolva melhor em altas concentrações (Gopal 1987). Segundo Gopal (1987), E. crassipes acumula em seu tecido uma grande quantidade de nutrientes essenciais a sua existência, acumula ainda elementos traço e até metais pesados.

No Pantanal as mudanças sazonais causadas pela variação do nível da água mostrou variação no ambiente aquático e na planície de inundação evidenciando variação limnológica temporal e espacial, por causa da cobertura de macrofitas, vento, gênese, padrão de drenagem, diversidade do ambiente terrestre ao redor da área, entre outros fatores já visto por Nogueira (1989); Panoso (1993); Hamilton et al. (1996), Da Silva e Figueiredo (1999), Ramachandra et al. (2002), Da Silva et al (2012), Abdo et al (2014), Da Silva (2015), Nunes et al. (2017), Santos et al. (2017), Nunes et al (2006), Nunes et al (2005), Nunes et al (2009), Nunes et al (2012a), Nunes et al (2012b), Nunes et al (2020) Nunes e Da Silva (2021).

Este estudo teve como objetivo analisar a variação temporal e espacial dos principais nutrientes na biomassa de $E$. crassipes em três pontos de amostragem no Sistema de Baías Cacororé-Sinhá Mariana. 


\section{Metodologia}

Para as coletas de campo, foram selecionados três pontos amostrais no Sistema de Baías Chacororé-Sinhá Mariana sendo o primeiro (ponto 1) na Baía de Chacororé localizado nas coordenadas 21k 0615537 e 8196165 UTM a 158m acima do nível do mar. Os pontos dois e três estão localizados na Baía de Sinhá Mariana, sendo o ponto 2 siuado na confluência da Baía com o Rio Mutum foi denominado como Sinhá Mariana/Mutum (21k 0615957 e 8195963 UTM e 153m acima do nível do mar. O ponto 3 esta localizado na transição entre a Baía Sinhá Mariana e Chacororé (21k 0615826, 8192922 a 147m acima do nível do mar) neste ponto ainda que situado em Sinhá Mariana recebe água de Chacororé através do Corixo Do Mato. As coletas foram realizadas durante a estação seca de 2001 (Julho e Agosto) e durante a estação chuvosa de 2002 (Fevereiro e Março), em pontos amostrais situados na região litoranea.

A composição química da biomassa de Eichhorinia crassipes foi analisada quanto ao teor de conteúdo mineral, nitrogênio e fósforo total, cálcio, magnésio, sódio e potássio.

Para análise do teor de conteúdo mineral total foi pesado 0,5 gramas das estruturas de E. crassipes estas foram então queimadas a $550^{\circ} \mathrm{C}$, o resíduo restante é o conteúdo mineral da planta (Allen 1989).

Para a análise do Nitrogênio total e Fósforo total foi utilizada uma solução digestora ácida composta por Selênio, Lítio, Ácido Sulfúrico e Peróxido de Hidrogênio, em bloco digestor à temperatura de $340^{\circ} \mathrm{C}$ (Anderson \& Ingram, 1996). A determinação foi efetuada através do método colorimétrico (Golterman et al 1978; Mackereth et al., 1978; Carmouze 1994):

A determinação quantitativa de $\mathrm{Ca}, \mathrm{Mg}, \mathrm{K}$ e $\mathrm{Na}$ foi realizado pela técnica de Espectrofotometria de Chama e Absorção Atômica (Allen 1989; Anderson \& Ingram 1996).

Para análise dos dados foi utilizado o programa SPSS (Statistical Package for Social Science) ANOVA, Teste de Levene, Wilcoxon-Nemenyi-McDonald-Thompson.

\section{1 Área de Estudo}

O Pantanal Mato Grossense é uma depressão sazonalmente alagável, totalmente contida na bacia de drenagem do Alto Paraguai e compreende aproximadamente $140.000 \mathrm{Km}^{2}$ (Figura 1). Segundo a classificação de Koppen, ocorre no Pantanal o tipo climático AW - clima quente e úmido, com estação chuvosa no verão e estiagem no inverno, (Amaral Filho 1986 e Brown Jr 1986). Segundo Silva (1986) a precipitação pluviométrica de $1000 \mathrm{~mm}$ no setor oeste a $1300 \mathrm{~mm}$ nos setores sul e leste na região norte do Pantanal a precipitação é de 1500mm, podendo chegar a 2000mm segundo Adamoli (1982). 
Figura 1: Localização da área de estudo no sistema de baías Chacororé-Sinhá Mariana, Pantanal Mato-grossense, Barão de Melgaço, MT, Brasil.

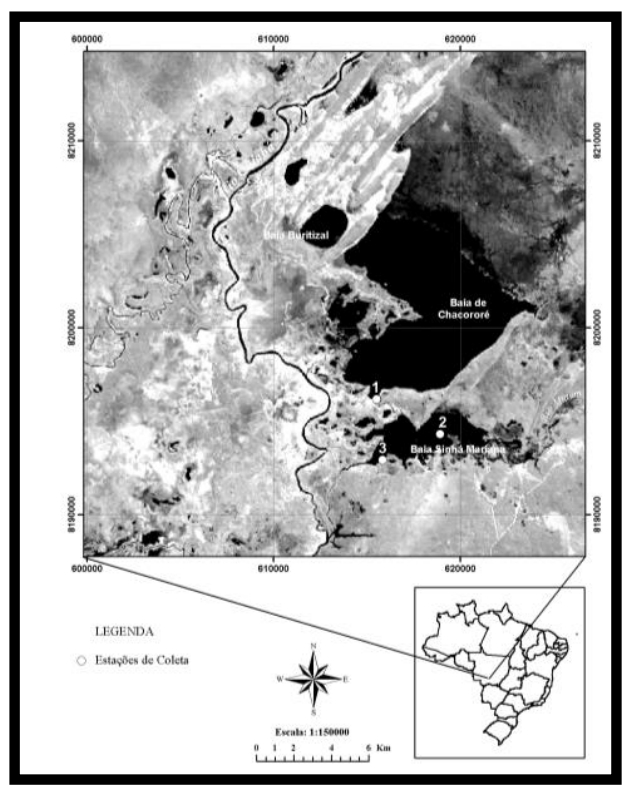

Fonte: Nunes, J. (2020).

Os estudos foram desenvolvidos no Sistema de baías Chacororé-Sinhá Mariana, situado entre as coordenadas $16^{\circ} 14^{\prime}$ a $16^{\circ} 16^{\prime}$ latitude Sul e $55^{\circ} 55^{\prime}$ a $55^{\circ} 58^{\prime}$ de longitude Oeste, à jusante da cidade de Barão de Melgaço.

Segundo Pinto-Silva (1980) a baía Chacororé apresenta águas túrbidas, formato semicircular situada a 125,20m, comprimento máximo, 10,18Km, largura máxima, 9,88Km, largura média, 6,00Km, profundidade máxima, 4,00m, profundidade média, 2,75m, volume, $178,6 \times 10^{6} \mathrm{~m}^{3}$, área, $64,92 \mathrm{Km}^{2}$.

A baía de Sinhá Mariana possui águas pretas, é formada por um alargamento do rio Mutum, e deságua no rio Cuiabá. Segundo Pinto-Silva (1980), possui formato alongado, comprimento máximo, 8,75Km, largura máxima, 2,67Km, largura média, 1,29Km, profundidade máxima, 4,75m, profundidade média, 3,58m, volume, 40,40 x $10^{6} \mathrm{~m}^{3}$, área $11,25 \mathrm{Km}^{2}$.

\section{Resultados}

\subsection{Conteúdo mineral}

O conteúdo mineral de cada mês de coleta demonstrou que as maiores porcentagens em todas as estações de coleta foram sempre obtidos durante a estiagem: a baía Chacororé apresentou valores de conteúdo mineral de 28,92\% $\pm 17,752 \%$,

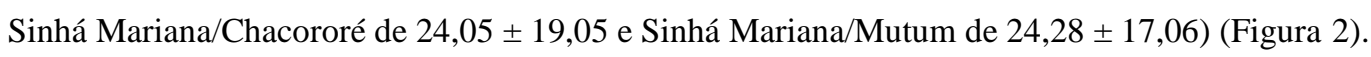


Figura 2: Variação do conteúdo mineral (\%) de E. crassipes e da lâmina da água no Sistema de Baías Chacororé-Sinha Mariana.

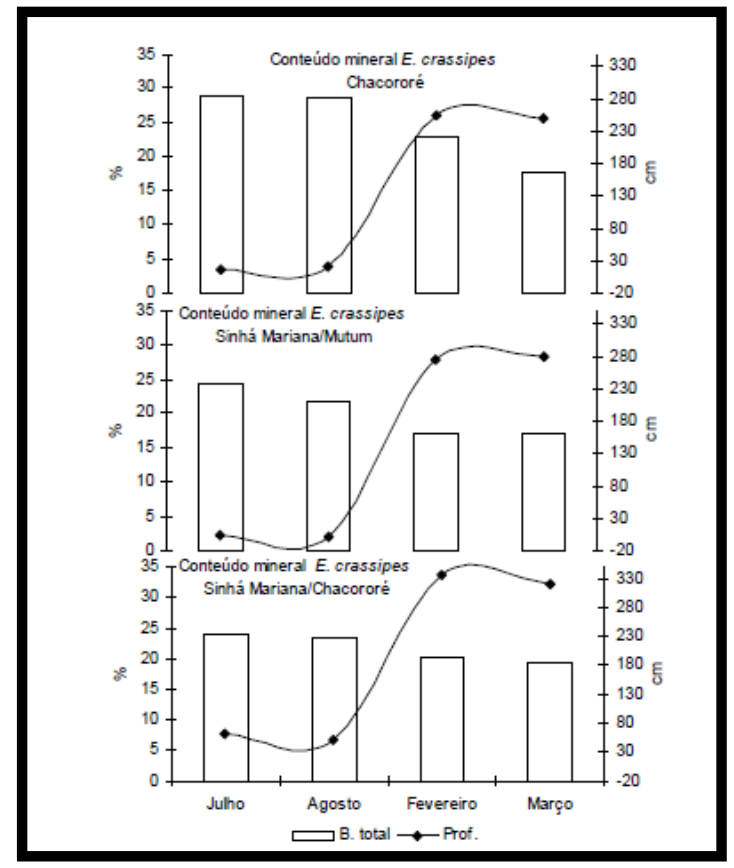

Fonte: Autores (2021).

As estruturas de E. crassipes que apresentaram maior teor de conteúdo mineral foram em Chacororé sendo raiz $56,17 \%$, > estolão 43,37\%, > rizoma 26,91\%, > detrito 31,61\%, > pecíolo 19,18\% > limbo 15,78\% (Figura 3a).

Em Sinhá Mariana/Mutum praticamente não houve variação do teor de conteúdo mineral (N=36, p > 0,05, r2 0,86) para as estruturas de E. crassipes entre estiagem e cheia a não ser a raiz que apresentou conteúdo mineral mais elevado durante a estiagem. As concentrações foram raiz 50,87\%, > detrito $26,08 \%,>$ rizoma 27,75 , > estolão $21,84 \%$, > pecíolo $17,27 \%$ > limbo $15,51 \%$ (Figura 3b).

Em Sinhá Mariana/Chacororé não foi observada diferença significativa entre estiagem e cheia para as estruturas de $E$. crassipes $(\mathrm{N}=36, \mathrm{p}>0,05, \mathrm{r} 20,78)$ as concentrações foram raiz57,14\%, > rizoma $27,75 \%$, > estolão $25,76 \%$, > detrito $24,95 \%$, > pecíolo 17,38\% > limbo 14,83 (Figura 3c). 
Figura 3: Variação do conteúdo mineral (\%) da biomassa de E. crassipes na Baía Chacororé (a), Baía Sinhá Mariana/Mutum (b) e Baía Sinhá Mariana/Chacororé (c) durante a estiagem de 2001 e a cheia de 2002 no Sistema de Baías Chacororé-Sinhá Mariana.
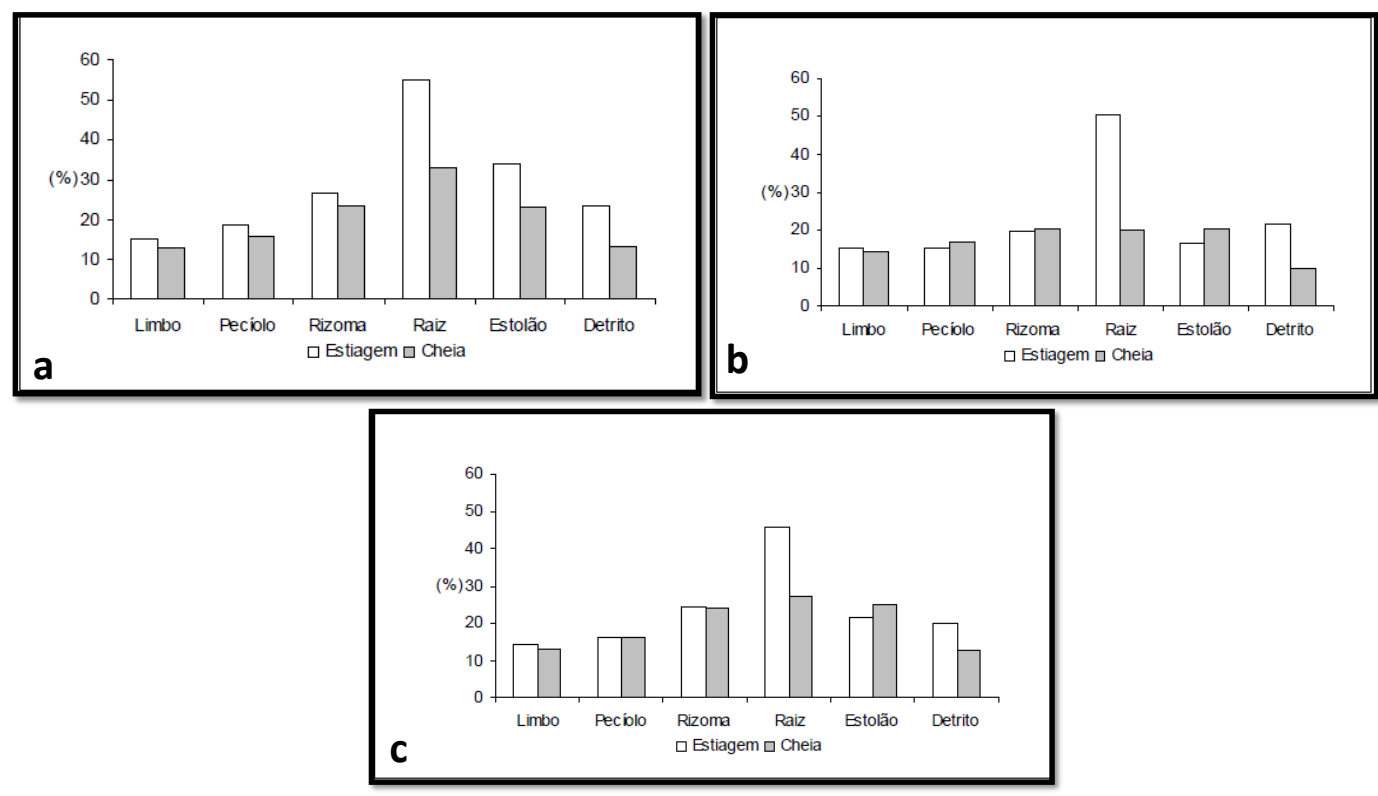

Fonte: Autores (2021).

\subsection{Composição química de $E$. crassipes (Fósforo)}

A concentração de fósforo na biomassa de E. crassipes foi inversa ao pulso de inundação, sendo maior no período de estiagem em todas as estações de coleta (Figura 4).

Figura 4: Concentração de fósforo na biomassa (mg.g-1) de E. crassipes e variações do pulso de inundação no Sistema de baías Chacororé-Sinhá Mariana, nos meses de julho e agosto de 2001 e fevereiro e março de 2002.

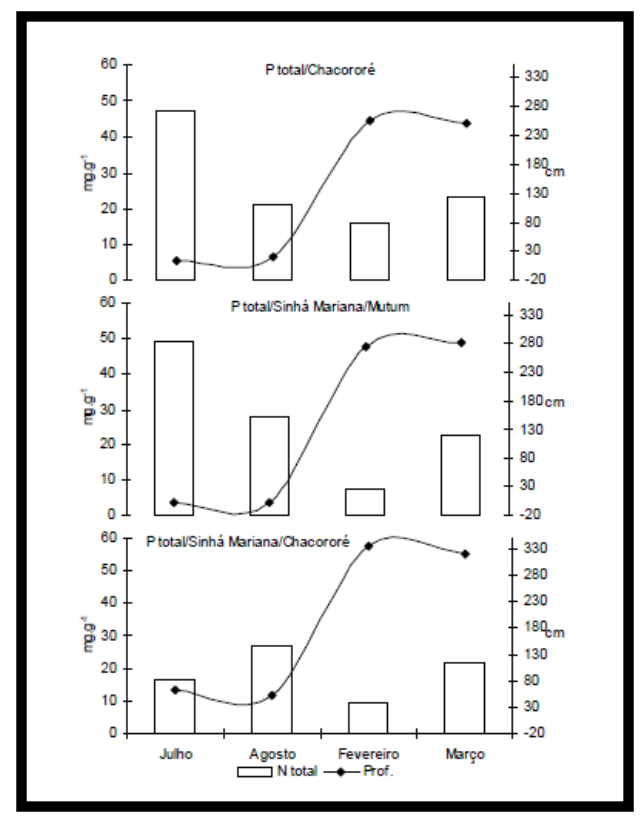

Fonte: Autores (2021). 
Os resultados de fósforo analisados na biomassa de E. crassipes na baía de Chacororé, mostraram que o máximo de fósforo em todas as partes da planta foi obtido no período de estiagem. As estruturas da planta que apresentaram maior concentração de fósforo foram limbo $(6,69 \mathrm{mg} . \mathrm{g}-1)>$ estolão $(6,31 \mathrm{mg} . \mathrm{g}-1)>$ seguidos da raiz $(5,72 \mathrm{mg} . \mathrm{g}-1)>$ pecíolo (5,65mg.g-1) > rizoma (5,39mg.g-1) > detrito (4,36mg.g-1) Na cheia, as estruturas apresentaram mudanças nas concentrações sendo detectado no rizoma $(4,17 \mathrm{mg} . \mathrm{g}-1)>$ estolão $(3,87 \mathrm{mg} . \mathrm{g}-1)>$ limbo $(3,73 \mathrm{mg} . \mathrm{g}-1)>$ pecíolo $(2,89 \mathrm{mg} . \mathrm{g}-1)>$ raiz (2,71mg.g-1) > detrito (2,25mg.g-1) (Figura 5a).

Figura 5: Concentração de fósforo (mg.g-1) na biomassa de E. crassipes no Sistema de baías Chacororé-Sinhá Mariana, na estiagem de 2001 e cheia de 2002, Em Chacororé (a), Sinhá Mariana/Mutum (b), Sinha Mariana/ Chacororé (c) e P total (d) em E. crassipes.

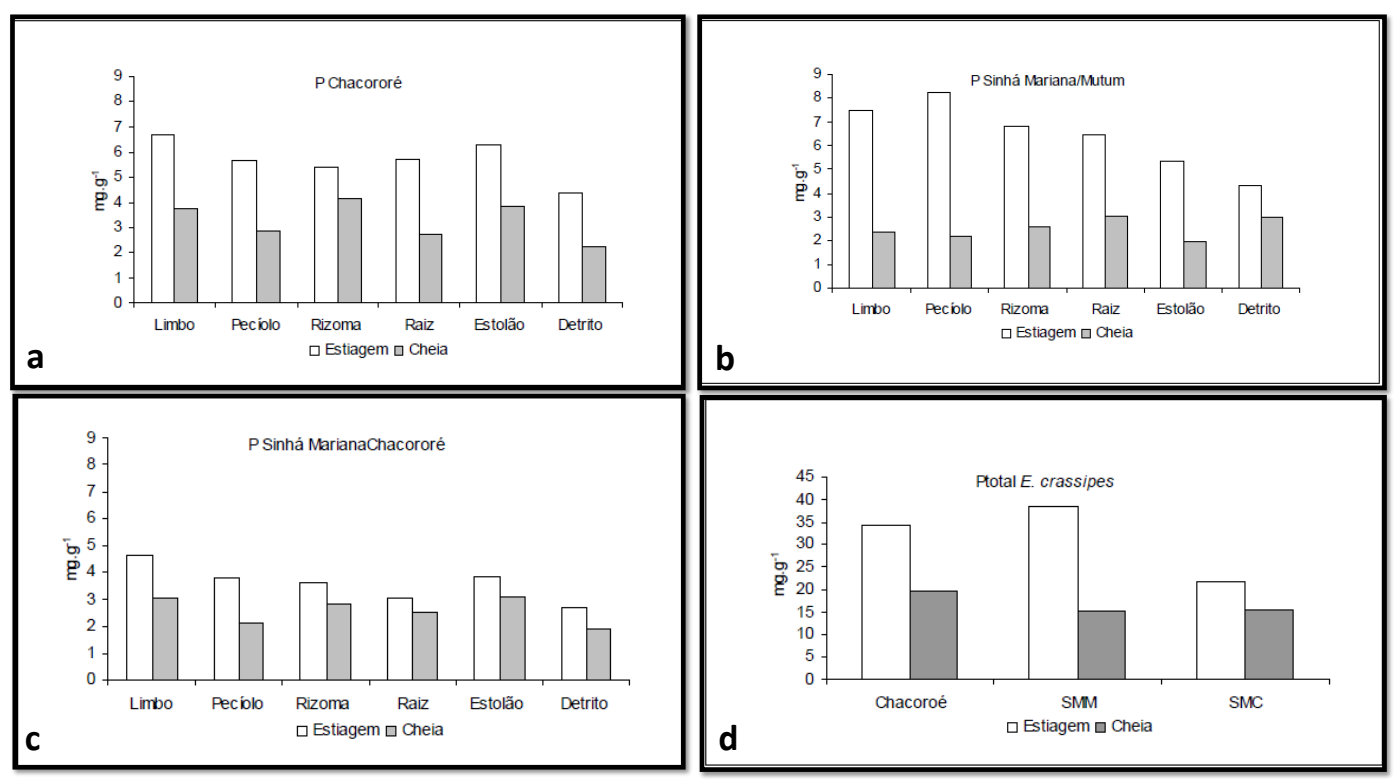

Fonte: Autores (2021).

A estiagem também foi o período hidrológico que apresentou maior concentração de fósforo na biomassa de $E$. crassipes na baía Sinhá Mariana/Mutum. A sequência de concentração de fósforo na biomassa da planta foi pecíolo (8,25mg.g1) > limbo (7,47mg.g-1) > rizoma (6,83mg.g-1) > raiz (6,45mg.g-1) > estolão (5,39mg.g-1) > detrito (4,33mg.g-1). Durante a cheia as concentrações foram raiz $\left(3,04 \mathrm{mg} \cdot \mathrm{g}^{-1}\right)>$ detrito $(3,02 \mathrm{mg} \cdot \mathrm{g}-1)>$ rizoma $(2,60 \mathrm{mg} . \mathrm{g}-1)$, limbo $(2,34 \mathrm{mg} . \mathrm{g}-1)>$ pecíolo (2,19mg.g-1) > estolão (1,97mg.g-1) (Figura 5b).

Na baía Sinhá Mariana/Chacororé as concentrações mais elevadas foram obtidas na estiagem a ordem de concentração observada foi limbo (4,66mg.g-1) > estolão (3,85mg.g-1) > Pecíolo (3,78mg.g-1) > rizoma (3,59mg.g-1) > raiz (3,03mg.g-1) > detrito (2,72mg.g-1). Na cheia os valores observados foram estolão (3,11 mg.g-1) > limbo (3,04mg.g-1) > rizoma (2,81mg.g-1) $>$ raiz $(2,50 \mathrm{mg} . \mathrm{g}-1)>$ pecíolo $(2,15 \mathrm{mg} . \mathrm{g}-1)>$ detrito $(1,88 \mathrm{mg} . \mathrm{g}-1)$ (Figura 5c). Na cheia foram observadas as menores concentrações de fósforo nas três estações de coleta, sendo Sinhá Mariana/Mutum a estação que apresentou os maiores valores de fósforo em E. crassipes.

Quando as estruturas de E. crassipes foram avaliadas estatisticamente para verificar se haviam variações significativas espacial e temporal entre as concentrações de fósforo os resultados obtidos foram os seguintes, no limbo houve diferença significativa apenas para período hidrológico (temporal) sendo $\mathrm{N}=36, \mathrm{p}<0,01, \mathrm{r} 2=0,38$, sendo que não houve diferença espacial. Pecíolo apresentou diferença significativa também temporal sendo $\mathrm{N}=36, \mathrm{p}<0,01, \mathrm{r} 2=0,58$. Rizoma não apresentou 
diferença estatística significativa espacial e nem temporal. Raiz não apresentou diferença espacial ou temporal. Estolão apresentou diferença significativa temporal $\mathrm{N}=36, \mathrm{p}<0,05, \mathrm{r} 2=0,25$. Detrito não apresentou diferença estatística significativa.

Como pode ser observado na figura $5 \mathrm{~d}$, todas as estações de coleta apresentaram maior concentração de fósforo durante a estiagem. Sinhá Mariana/Mutum foi a estação que registrou a maior concentração de fósforo na biomassa de $E$. crassipes durante a estiagem (38,72 mg.g-1) enquanto Chacororé apresentou a maior concentração durante a cheia (19,62mg.g1). Fósforo total apresentou diferença estatística significativa apenas temporal, $\mathrm{N}=36, \mathrm{p}<0,05, \mathrm{r} 2=0,57$.

\subsection{Composição química de $E$. crassipes (Nitrogênio)}

Na figura 6 observa-se que a concentração de nitrogênio teve uma relação positiva com o pulso de inundação, apresentando maiores concentrações quanto maior a coluna d'água, sendo Chacororé a estação que apresentou maior concentração de nitrogênio em E. crassipes.

Figura 6: Concentração de nitrogênio (mg.g-1) na biomassa de E. crassipes e pulso de inundação no Sistema de baías Chacororé-Sinhá Mariana, nos meses de julho e agosto de 2001 e fevereiro e março de 2002.

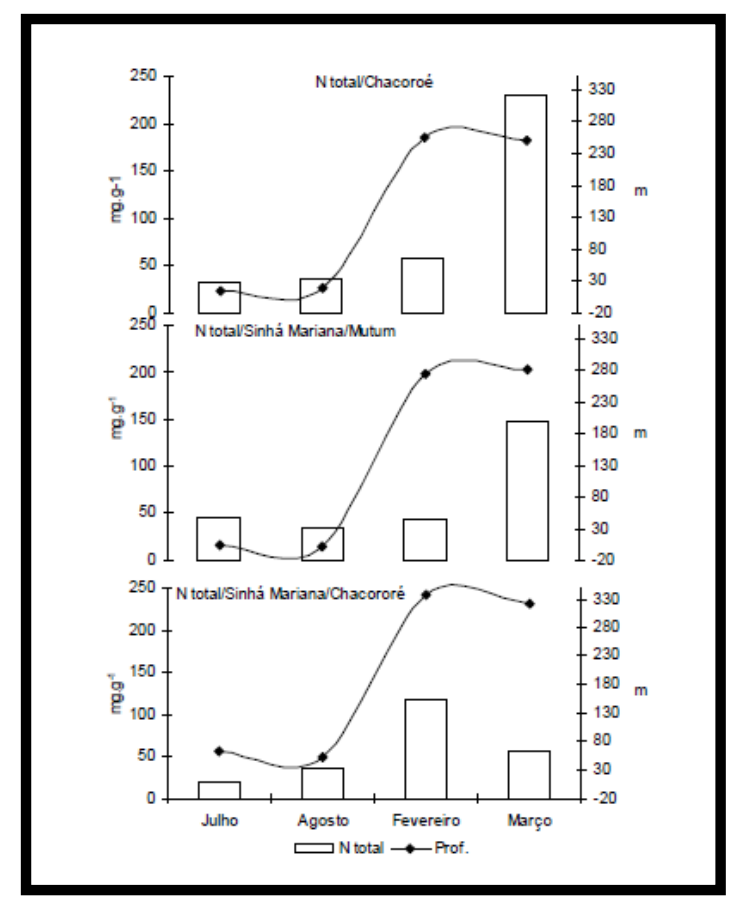

Fonte: Autores (2021).

Nitrogênio apresentou comportamento oposto ao fósforo apresentando na estação Chacororé as maiores concentrações no período de maior cheia. As concentrações de nitrogênio nas porções da planta foram limbo $(64,72 \mathrm{mg}$.g-1) > rizoma (48,66mg.g-1) > raiz (35,89mg.g-1) > detrito (30,53mg.g-1) > pecíolo (29,59mg.g-1) > estolão (22,02mg.g-1) Figura 7 a. 
Figura 7: Concentração de nitrogênio (mg.g-1) na biomassa de E. crassipes no Sistema de baías Chacororé-Sinhá Mariana, durante a estiagem de 2001 e a cheia de 2002. Em Chacororé (a), Sinhá Mariana/Mutum (b), Sinha Mariana/ Chacororé (c) e N total (d) em E. crassipes.

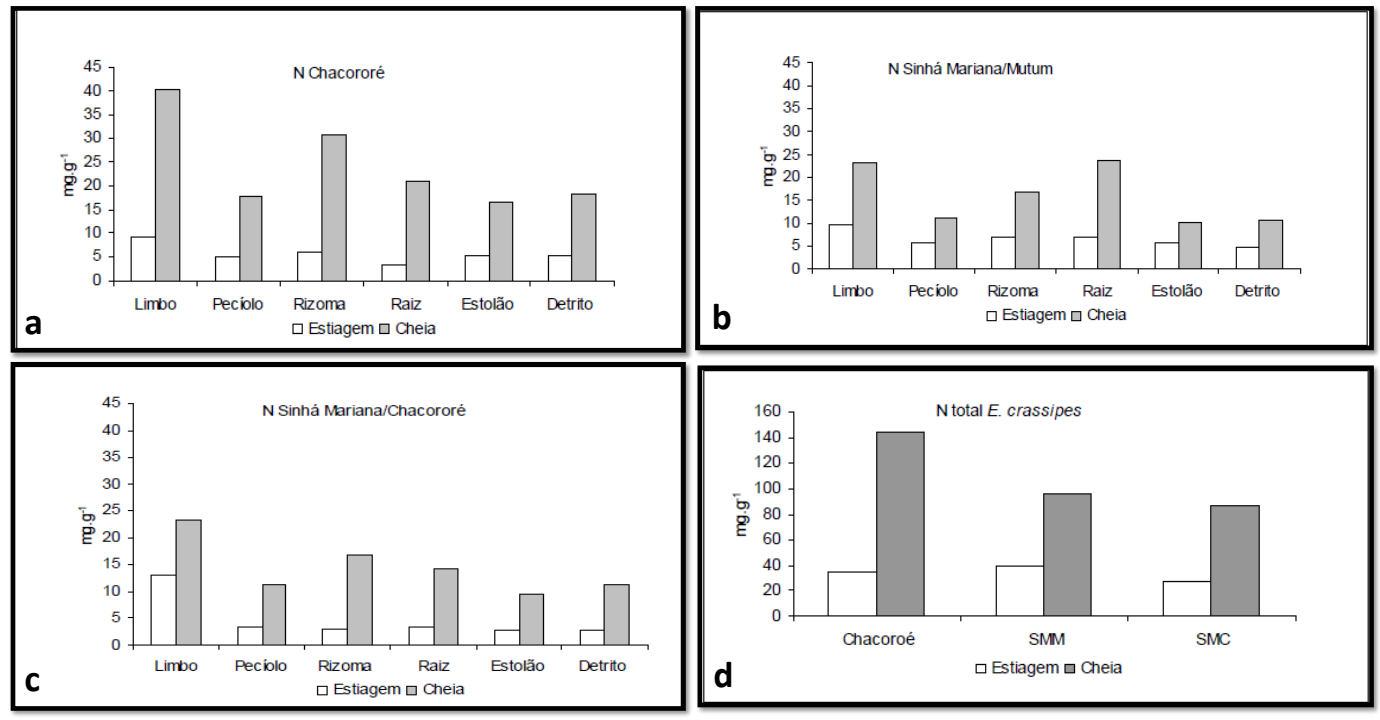

Fonte: Autores (2021).

Em Sinhá Mariana/Mutum as maiores concentrações de nitrogênio também foram obtidas na cheia, a concentração de nitrogênio nas porções da planta foram as seguintes,raiz $(38,21 \mathrm{mg} . g-1)>$ limbo $(35,63 \mathrm{mg} . g-1)>$ rizoma $(26,24 \mathrm{mg}$.g-1) > pecíolo (16,64mg.g-1) > estolão (16,23mg.g-1) > detrito (14,82mg.g-1) (Figura 7b).

Na estação Sinhá Mariana/Chacororé apresentou maiores concentrações de nitrogênio na cheia as concentrações observadas foram limbo (34,50mg.g-1) > rizoma (23,82mg.g-1) > raiz (20,39mg.g-1) > detrito $(15,14 \mathrm{mg} . \mathrm{g}-1)>$ pecíolo (15,01mg.g-1) > estolão (10,11mg.g-1) (Figura 7c).

Quando as estruturas de E. crassipes foram avaliadas estatisticamente para verificar se haviam variações significativas espacial e temporal entre as concentrações de nitrogênio, os resultados obtidos foram os seguintes, no limbo houve diferença significativa apenas para período hidrológico (temporal) sendo $\mathrm{N}=36, \mathrm{p}<0,05, \mathrm{r} 2=0,47$, sendo que não houve diferença espacial. Pecíolo apresentou diferença significativa também temporal sendo $\mathrm{N}=36, \mathrm{p}<0,01$, $\mathrm{r} 2=0,44$. Rizoma apresentou diferença estatística significativa temporal, $\mathrm{N}=36, \mathrm{p}<0,01, \mathrm{r} 2=0,57$. Raiz apresentou diferença temporal, $\mathrm{N}=36, \mathrm{p}<0,01, \mathrm{r} 2=$ 0,73. Estolão apresentou diferença significativa temporal $\mathrm{N}=36, \mathrm{p}<0,01, \mathrm{r} 2=0,49$. Detrito apresentou diferença estatística significativa temporal, $\mathrm{N}=36, \mathrm{p}<0,01, \mathrm{r} 2=0,60$.

O período hidrológico que apresentou maior concentração de nitrogênio em E. crassipes foi a cheia para todas as estações de coleta, sendo Chacororé a que apresentou maior concentração desse nutriente na planta (144,64mg.g-1). Na estiagem a concentração de nitrogênio não variou significativamente entre as estações de coleta: 34,63 mg.g-1 em Chacororé, 40,03mg.g-1 em Sinhá Mariana/Mutum e de 28,21mg.g-1 em Sinhá Mariana/Chacororé (Figura7d). Nitrogênio total apresentou diferença estatística significativa apenas temporal, $\mathrm{N}=36, \mathrm{p}<0,01, \mathrm{r} 2=0,34$.

\subsection{Composição química de E. crassipes (Sódio)}

Na figura 8 observamos que a concentração de sódio em toda planta são maiores no período de águas baixas (estiagem), para duas das estações de coleta, sendo que Chacororé foi a que apresentou a maior concentração durante o mês de julho (13,14mg.g-1). Sinhá Mariana/Chacororé também apresentou maior concentração em julho (9,91mg.g-1). Na estação 
Sinhá Mariana/Mutum a maior concentração foi obtida na cheia (11,99mg.g-1). Em geral a concentração não variou significativamente no período de estudo.

Figura 8: Concentração de sódio (mg.g-1) na biomassa de E. crassipes e nível d’água no Sistema de baías Chacororé-Sinhá Mariana, nos meses de julho e agosto de 2001 e fevereiro e março de 2002.

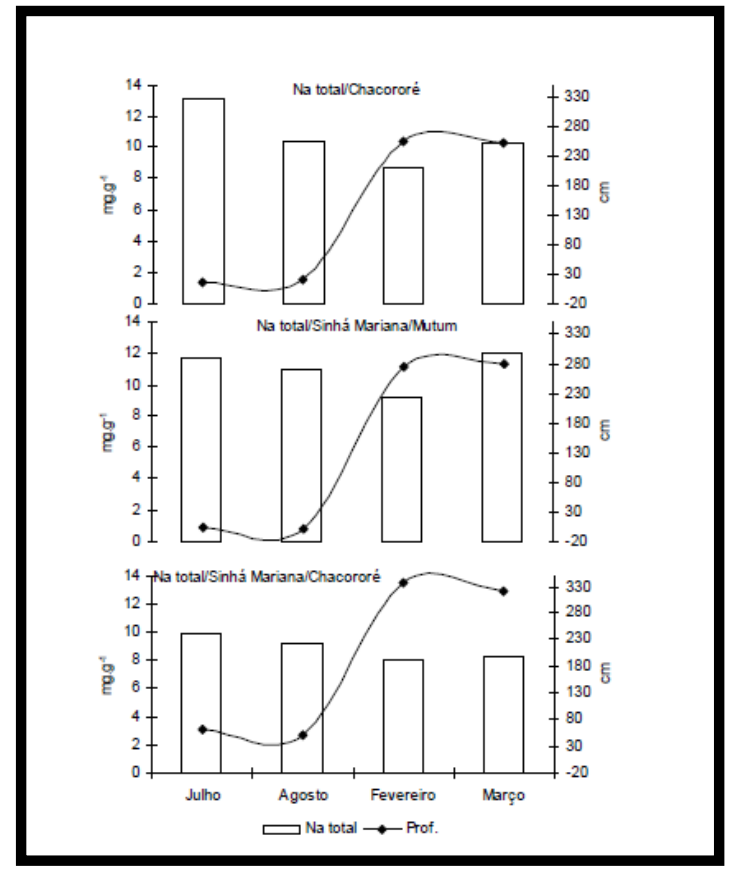

Fonte: Autores (2021).

A figura 9a resume os valores de sódio, em Chacororé. A concentração de sódio em E. crassipes não apresentou uma tendência de acumular concentração nos períodos de cheia e estiagem. Entre as porções da planta, o estolão apresentou maior concentração de sódio em todos os meses estudados. As maiores concentrações para cada estrutura da planta variam entre estiagem e cheia sendo que na estiagem foram observadas as seguintes concentração: estolão 5,16mg.g-1, > rizoma apresentou 2,51mg.g-1 > detrito 1,23mg.g-1 > pecíolo $1,14 \mathrm{mg} . g-1$ > raiz 0,90mg.g-1 > limbo 0,80mg.g-1. Na cheia as concentrações observadas foram: rizoma 2,74mg.g-1 > estolão 2,59mg.g-1 > raiz 1,34mg.g-1 > detrito 1,17mg.g-1 > pecíolo 0,88mg.g-1 > limbo 0,74mg.g-1.

Em Sinhá Mariana/Mutum, o sódio também não apresentou um determinado mês do ciclo hidrológico que apresentasse maior concentração. Na estiagem, a sequência das maiores concentrações foram: rizoma 3,23mg.g-1 > estolão 2,88mg.g-1 > raiz 1,75mg.g-1 > detrito $1,31 \mathrm{mg} . \mathrm{g}-1$ > pecíolo $1,16 \mathrm{mg} . \mathrm{g}-1>$ limbo $0,96 \mathrm{mg} . \mathrm{g}-1$. Durante a cheia as concentrações medidas foram : estolão 2,75mg.g-1 > rizoma 2,48 mg.g-1 > raiz 2,38mg.g-1 > detrito 1,23 mg.g-1 > pecíolo 1,18mg.g-1 > limbo 0,54mg.g-1 (Figura 9b).

A estação Sinhá Mariana/Chacororé apresentou as mesmas variações observadas nas outras estações de coleta, não aparecendo um mês em que o sódio apresentasse concentrações mais elevadas em todas as estruturas da planta. Os valores de concentração mais elevados foram observados durante a estiagem, rizoma apresentou a maior concentração sendo 2,61mg.g-1 > estolão 1,75mg.g-1 > detrito 1,62mg.g-1 > raiz 1,42mg.g-1 > pecíolo 1,27mg.g-1 > limbo 0,86mg.g-1 . Durante as cheia as concentrações de sódio na biomassa de E. crassipes foram: estolão 2,07 mg.g-1 > raiz 1,69 mg.g-1 > rizoma 1,64 mg.g-1 > detrito 1,08 mg.g-1 > pecíolo 0,97 mg.g-1 > limbo 0,70 mg.g-1 (Figura 9c). 
Figura 9: Concentração de sódio (mg.g-1) na biomassa de E. crassipes no Sistema de baías Chacororé-Sinhá Mariana, durante a estiagem de2001 e a cheia de 2002. Em Chacororé (a), Sinhá Mariana/Mutum (b), Sinha Mariana/ Chacororé (c) e Na total (d) em E. crassipes.
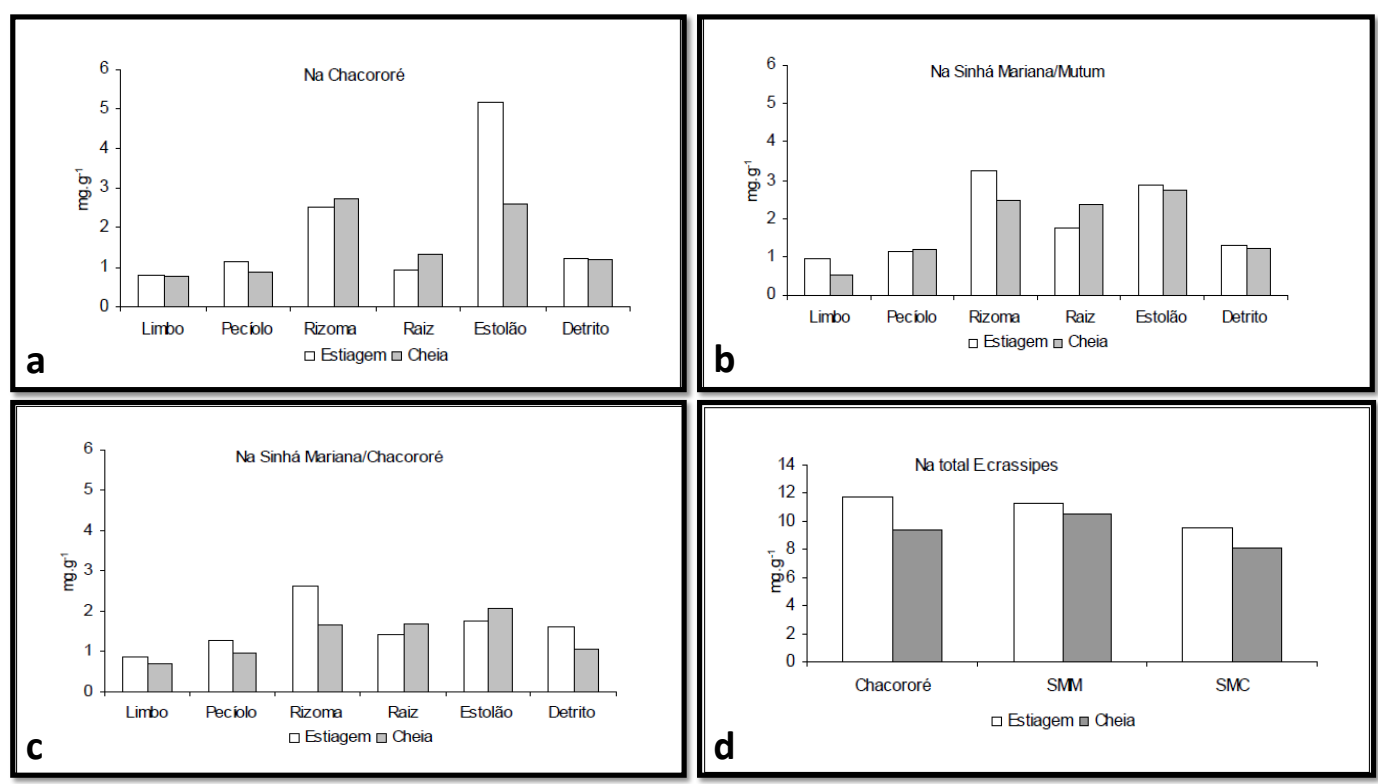

Fonte: Autores (2021).

Quando as estruturas de E. crassipes foram avaliadas estatisticamente para verificar se haviam variações significativas espacial e temporal entre as concentrações de sódio, os resultados obtidos foram os seguintes, no limbo houve diferença significativa apenas para período hidrológico (temporal) sendo $\mathrm{N}=36, \mathrm{p}<0,01, \mathrm{r} 2=0,39$, sendo que não houve diferença espacial. Pecíolo não apresentou diferença significativa temporal ou espacial. Rizoma também não apresentou diferença estatística significativa temporal ou espacial. Raiz apresentou diferença espacial (entre estações de coleta), $\mathrm{N}=36, \mathrm{p}<0,01, \mathrm{r} 2=$ 0,47. Estolão não apresentou diferença significativa temporal ou espacial. Detrito também não apresentou diferença estatística significativa temporal ou espacial.

Na figura 9d observamos que a concentração de sódio no sistema de baías Chacororé-Sinhá Mariana é maior na estiagem para as três estações estudadas, e que Chacororé apresenta maior concentração média de sódio na cheia (7,74mg.g-1), Sinhá Mariana/Mutum apresenta as maiores concentrações na estiagem (10,55mg.g-1), Sinhá Mariana/Chacororé apresentou valores intermediários tanto para estiagem quanto para cheia. Sódio não apresentou diferença estatística significativa temporal ou espacial.

\subsection{Composição química de $E$. crassipes (Cálcio)}

Sinhá Mariana/Mutum apresentou a maior concentração de Ca das áreas estudadas (15,07mg.g-1) na cheia. A concentração de cálcio nesta estação parece acompanhar o nível d’água na baía. Chacororé também apresentou a maior concentração de cálcio durante a cheia (12,63 mg.g-1, março), enquanto Sinhá Mariana/Chacororé teve sua maior concentração durante o período de estiagem (12,76 mg.g-1, julho) (Figura 10). 
Figura 10: Concentração de cálcio (mg.g-1) na biomassa de E. crassipes e pulso de inundação no Sistema de baías ChacororéSinhá Mariana, nos meses de julho e agosto de 2001 e fevereiro e março de 2002.

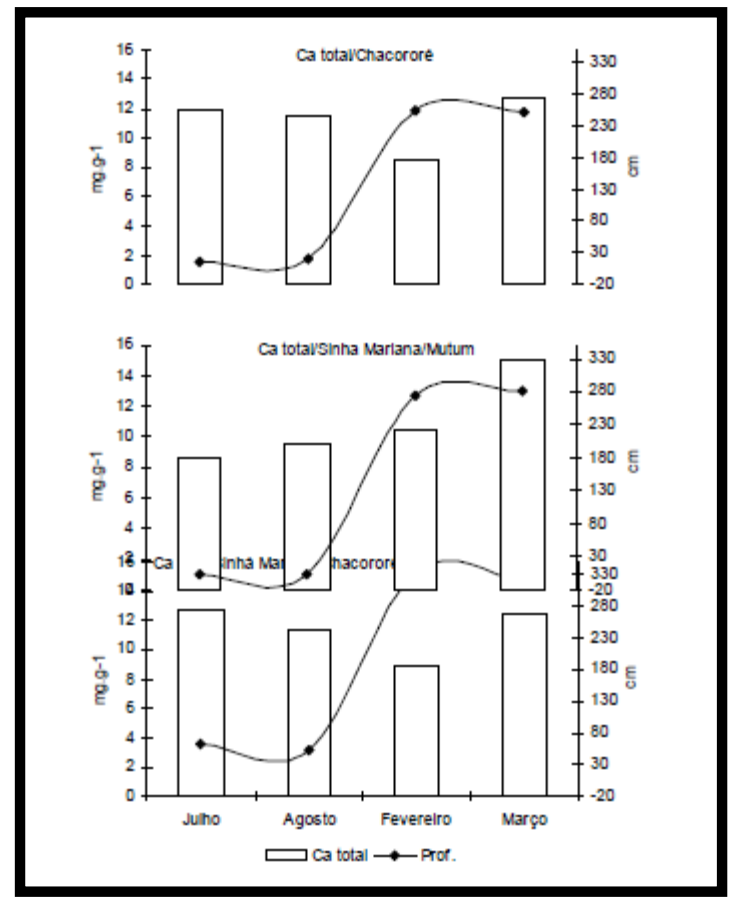

Fonte: Autores (2021).

As maiores concentrações de cálcio para o limbo e detrito foram obtidas na cheia, enquanto rizoma, pecíolo e estolão apresentaram maiores concentrações na estiagem. A raiz não apresentou variação. As maiores concentrações na estiagem foram: limbo 3,53mg.g-1 > pecíolo 3,20mg.g-1 > detrito 2,04mg.g-1 > rizoma 1,71mg.g-1 > estolão 0,85mg.g-1 > raiz 0,33mg.g-1 . Na cheia as concentrações foram: limbo 3,35 mg.g-1 > pecíolo 2,99 mg.g-1 > detrito 2,67mg.g-1 > rizoma 0,67 mg.g-1 > estolão 0,53 mg.g-1 > raiz 0,36 mg.g-1 (Figura 11a).

Em Sinhá Mariana/Mutum Cálcio apresentou maiores concentrações no período de cheia para todas as estruturas da planta, as concentrações foram: limbo 3,71mg.g-1 > pecíolo 2,63mg.g-1 > detrito 2,38mg.g-1 > rizoma 1,94mg.g-1 > estolão 1,32mg.g-1 > raiz 0,80mg.g-1. na estiagem as concentrações foram: limbo 2,78 mg.g-1 > pecíolo 2,07 mg.g-1 > detrito 1,67 mg.g-1 > rizoma 1,48 mg.g-1 > estolão 0,77 mg.g-1 > raiz 0,28 mg.g-1 (Figura 11b).

A estação Sinhá Mariana/Chacororé apresentou comportamento semelhante ao de Chacororé não demonstrando uma tendência de concentrações durante a estiagem ou cheia nas estruturas da planta, ficando limbo, detrito e raiz com maiores concentrações na cheia e pecíolo, rizoma e estolão na estiagem. As maiores concentrações observadas na estiagem foram: pecíolo 3,09mg.g-1 > rizoma 3,01mg.g-1 >, limbo 2,40mg.g-1 > detrito 2,34mg.g-1 > estolão 0,87 mg.g-1 > raiz 0,31mg.g-1 . Na cheia detrito mostrou 3,19 mg.g-1 > pecíolo 2,97 mg.g-1 > limbo 2,90 mg.g-1 > rizoma 0,83 mg.g-1 > estolão 0,41 mg.g-1 $>$ raiz 0,36 mg.g-1 (Figura 11c). 
Figura 11: Concentração de cálcio (mg.g-1) na biomassa de E. crassipes no Sistema de baías Chacororé-Sinhá Mariana, nos meses de julho e agosto de 2001 e fevereiro e março de 2002. Em Chacororé (a), Sinhá Mariana/Mutum (b), Sinha Mariana/ Chacororé (c) e Ca total (d) em E. crassipes.

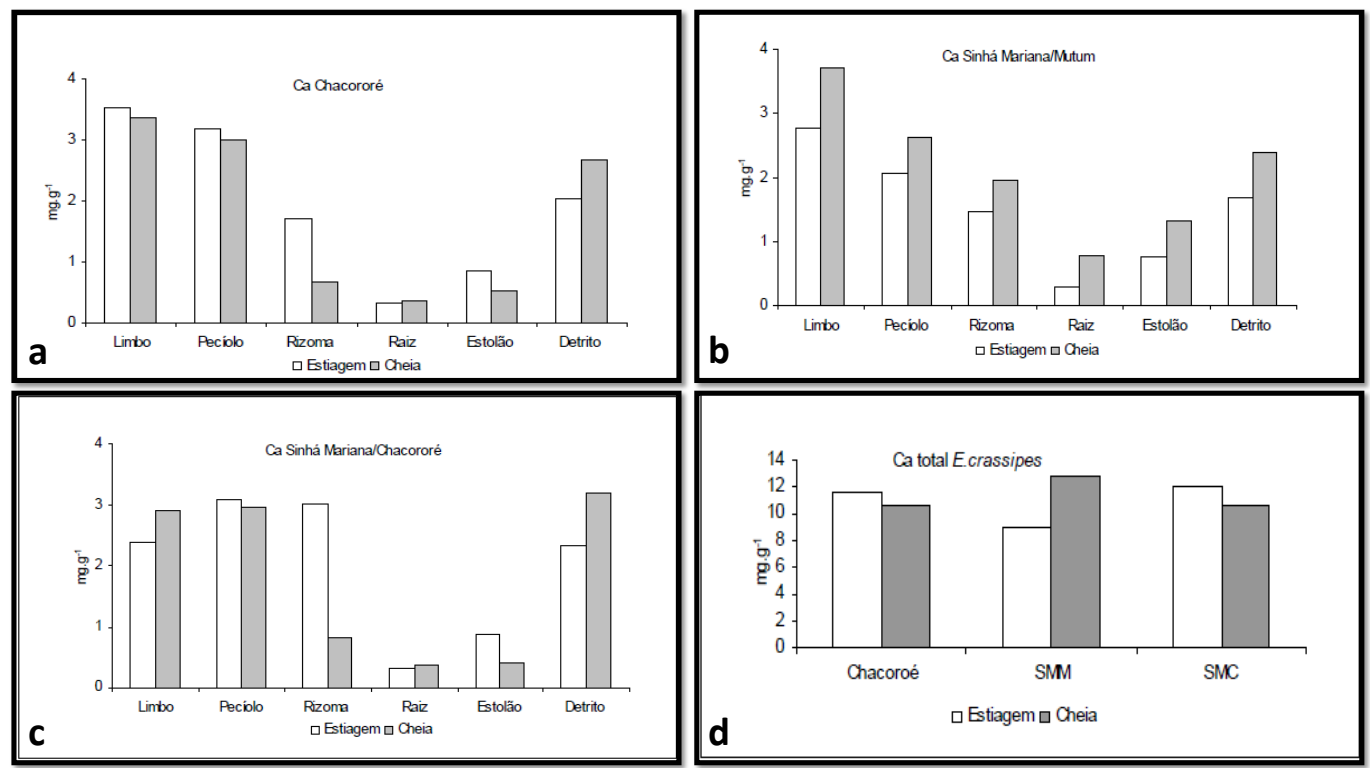

Fonte: Autores (2021).

Quando as estruturas de E. crassipes foram avaliadas estatisticamente para verificar se haviam variações significativas espacial e temporal entre as concentrações de cálcio, os resultados obtidos foram os seguintes, no limbo houve diferença significativa apenas espacial (entre as estações de coleta) sendo $\mathrm{N}=36, \mathrm{p}<0,01, \mathrm{r} 2=0,42$, sendo que não houve diferença temporal. Pecíolo apresentou diferença significativa espacial $\mathrm{N}=36, \mathrm{p}<0,01, \mathrm{r} 2=0,35$. Rizoma apresentou diferença estatística significativa temporal e tempo-espacial (quando comparada ao mesmo tempo espaço e tempo) $\mathrm{N}=36, \mathrm{p}<0,01, \mathrm{r} 2=0,85$ e $\mathrm{N}=36, \mathrm{p}<0,01, \mathrm{r} 2=0,82$ respectivamente. Raiz apresentou diferença espacial (entre estações de coleta), N=36, $\mathrm{p}<0,05, \mathrm{r} 2=$ 0,30 . Estolão apresentou diferença significativa tempo-espacial, $\mathrm{N}=36, \mathrm{p}<0,01, \mathrm{r} 2=0,51$. Detrito não apresentou diferença estatística significativa temporal ou espacial.

Durante a estiagem Sinhá Mariana/Chacororé apresentou a maior concentração de Cálcio nos tecidos de E. crassipes (12,02 mg.g-1) Chacororé apresenta valor intermediário (11,65 mg.g-1) e Sinhá Mariana/Mutum o menor valor (9,05mg.g-1). E na cheia Sinhá Mariana/Mutum passa a apresentar a maior concentração de cálcio em (12,79 mg.g-1), Sinhá Mariana/Chacororé e Chacororé quase não apresentaram variação entre as concentrações 12,021 mg.g-1 12,65 mg.g-1 respectivamente (Figura 11d). Cálcio apresentou diferença estatística significativa tempo-espacial N=36, p<0,01, r2 =0,30.

\subsection{Composição química de E. crassipes (Magnésio)}

A estação Sinhá Mariana/Mutum acumulou a maior quantidade de magnésio na sua biomassa (59,35mg.g-1), em relação a Sinhá Mariana/Chacororé que acumulou (53,35mg.g-1) e Chacororé que apresentou a menor concentração (44,33mg.g-1). Pode-se observar na figura (12) que o fator controlador da concentração de magnésio é o pulso de inundação, pois os maiores valores obtidos foram maiores durante a cheia em todas as estações. 
Figura 12: Concentração de magnésio (mg.g-1) na biomassa de E. crassipes no Sistema de baías Chacororé-Sinhá Mariana, nos meses de julho e agosto de 2001 e fevereiro e março de 2002.

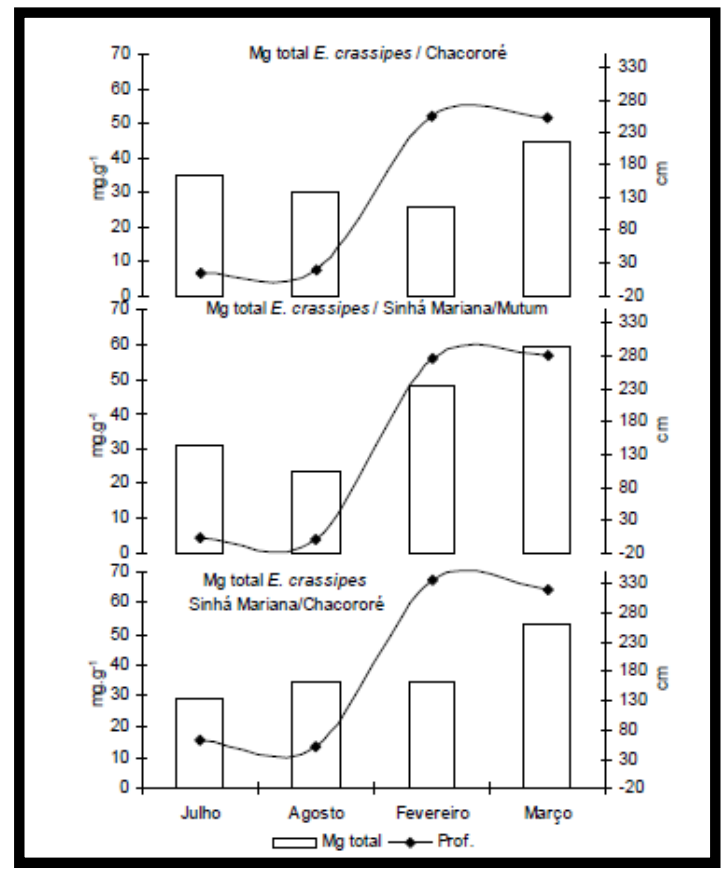

Fonte: Autores (2021).

Magnésio não apresentou padrão de variação de concentração, entre as áreas estudadas nos períodos estudados. O limbo e a raiz mostraram valores mais elevados na cheia, enquanto estolão, pecíolo, rizoma e detrito na estiagem. As concentrações observadas em Chacororé para as porções da planta durante a estiagem foram rizoma 10,05 mg.g-1 > estolão 7,37mg.g-1 > pecíolo 5,96mg.g-1 > limbo 4,70mg.g-1 > raiz 2,23mg.g-1 > detrito 2,20mg.g-1. Na cheia as maiores concentrações de magnésio na biomassa de E. crassipes foi: rizoma 9,75 mg.g-1 > raiz 5,97 mg.g-1 > pecíolo 5,91mg.g-1 > limbo 5,44 mg.g-1 > estolão 4,65 mg.g-1 > detrito 3,16 mg.g-1 (Figura 13a).

E. crassipes em Sinhá Mariana/Mutum obteve maiores concentrações de magnésio sempre durante a cheia, sendo registrado no rizoma 14,81mg.g--1 > raiz 11,36mg.g--1 > limbo 9,91mg.g--1 > pecíolo 9,90mg.g--1 > estolão 9,74mg.g--1 > detrito 5,51mg.g-1. durante a estiagem foram medidos os seguintes valores, rizoma 8,58 mg.g--1 > pecíolo 6,59 mg.g--1 > estolão 4,94 mg.g--1 > limbo 4,57 mg.g--1 > detrito 2,02 mg.g--1 > raiz 1,07 mg.g--1 (Figura 13b).

A estação Sinhá Mariana/Chacororé mostrou maior concentração de magnésio na cheia para todas as porções da planta, apresentando as seguintes concentrações, rizoma 11,25 mg.g-1 > raiz 7,42mg.g-1 > limbo 7,15mg.g-1 > pecíolo 6,80mg.g-1 > estolão 5,89mg.g-1> detrito 5,19mg.g-1 (Figura 13c). Durante a estiagem as concentrações foram, rizoma 8,82mg.g-1 > pecíolo 6,34mg.g-1 > estolão 5,13mg.g-1 > limbo 4,67mg.g-1 > detrito 3,66mg.g-1 > raiz 3,10mg.g-1.

Quando as estruturas de E. crassipes foram avaliadas estatisticamente para verificar se haviam variações significativas espacial e temporal entre as concentrações de magnésio, os resultados obtidos foram os seguintes, no limbo houve diferença significativa apenas temporal (entre estiagem e cheia) sendo $\mathrm{N}=36, \mathrm{p}<0,01, \mathrm{r} 2=0,40$, sendo que não houve diferença espacial. Pecíolo apresentou diferença significativa espacial $\mathrm{N}=36, \mathrm{p}>0,05, \mathrm{r} 2=0,30$. Rizoma apresentou diferença estatística significativa temporal e tempo-espacial (quando comparada ao mesmo tempo espaço e tempo) $\mathrm{N}=36, \mathrm{p}<0,01, \mathrm{r} 2=0,56$ e $\mathrm{N}=36, \mathrm{p}<0,01, \mathrm{r} 2=0,49$ respectivamente. Raiz apresentou diferença temporal, $\mathrm{N}=36, \mathrm{p}<0,05, \mathrm{r} 2=0,73$. Estolão apresentou diferença significativa tempo-espacial, $\mathrm{N}=36, \mathrm{p}<0,01, \mathrm{r} 2=0,45$. Detrito apresentou diferença estatística significativa temporal $\mathrm{N}=36, \mathrm{p}<0,01, \mathrm{r} 2=0,42$. 
Figura 13: Concentração de magnésio (mg.g-1) na biomassa de E. crassipes no Sistema de baías Chacororé-Sinhá Mariana, durante a estiagem de 2001 e a cheia de 2002. Em Chacororé (a), Sinhá Mariana/Mutum (b), Sinha Mariana/ Chacororé (c) e $\mathrm{Mg}$ total (d) em E. crassipes.

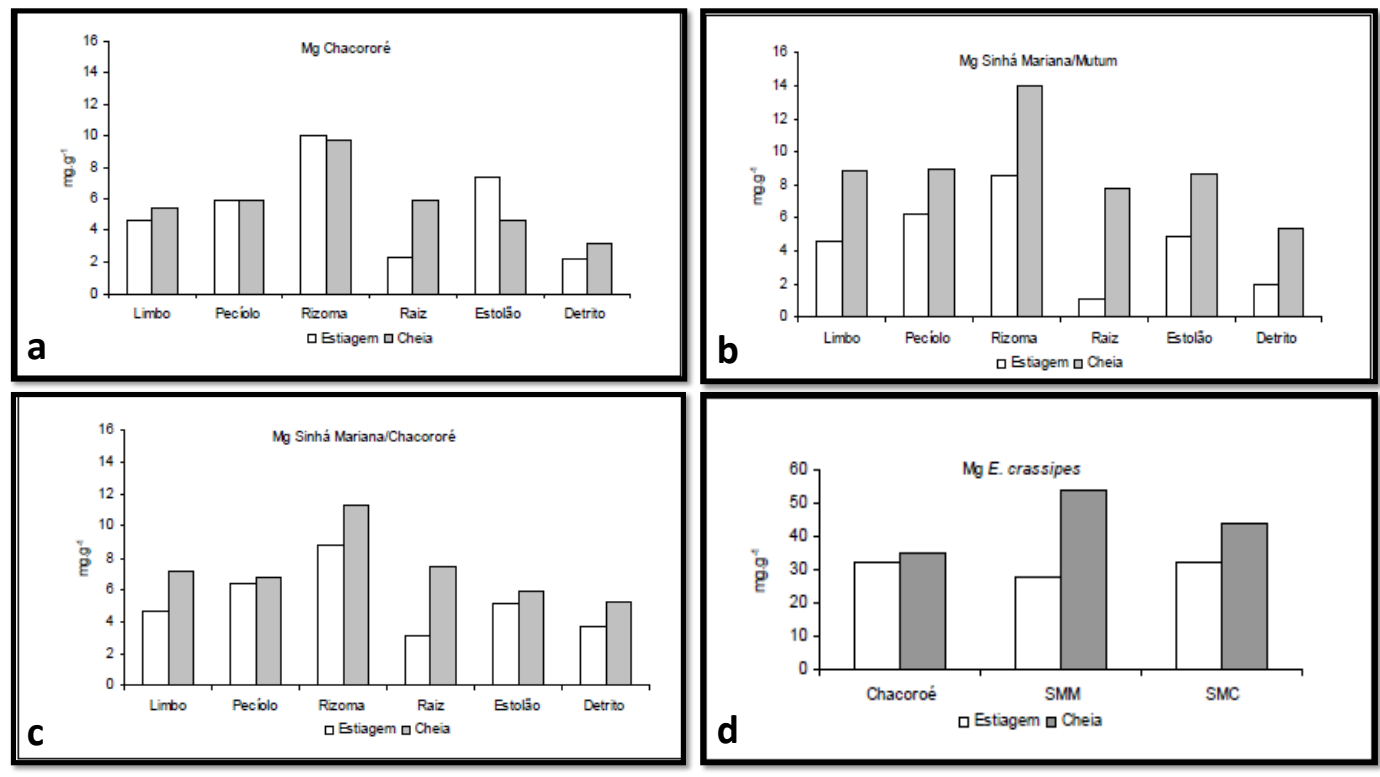

Fonte: Autores (2021).

Entre as três estações de coleta e entre período hidrológico, foi observado que na estiagem os valores de magnésio variaram pouco em Chacororé (32,51mg.g-1), seguido por Sinhá Mariana/Chacororé (31,73mg.g-1) e Sinhá Mariana/Mutum (27,47mg.g-1). Na cheia a variação é maior entre as estações. Sinhá Mariana/Chacororé obteve 43,70mg.g-1, Sinhá Mariana/Mutum apresentou a maior concentração com 53,62mg.g-1 e Chacororé 34,88mg.g-1 (Figura 13d). Magnésio apresentou diferença estatística significativa tempo-espacial $\mathrm{N}=36, \mathrm{p}<0,05, \mathrm{r} 2=0,49$ e temporal mais acentuada $\mathrm{N}=36, \mathrm{p}<0,01$, $\mathrm{r} 2=0,56$.

\subsection{Composição química de $E$. crassipes (Potássio)}

E. crassipes em Chacororé apresentou a maior concentração de potássio entre as estações estudadas. Os maiores valores nesta estação foram obtidos em julho e agosto (estiagem) e os menores em fevereiro e março (cheia), demonstrando maiores valores quando havia menos água e menores quando a coluna d'água está maior. Em Sinhá Mariana/Mutum não houve um padrão forte de variação. Em Sinhá Mariana/Chacororé o pulso de inundação parece influenciar a concentração de potássio, pois os valores mais elevados foram obtidos na cheia, os menores valores obtidos foram observados durante a estiagem, na cheia foram observados os maiores valores, as concentrações médias mais elevadas foram em Chacororé 181,71 mg.g-1 (julho), Sinhá Mariana/Mutum 154mg.g-1 e Sinhá Mariana/Chacororé 144,77mg.g-1 Figura 14. 
Figura 14: Concentração de potássio (mg.g-1) na biomassa de E. crassipes e altura da lâmina d'água no Sistema de baías Chacororé-Sinhá Mariana, nos meses de julho e agosto de 2001 e fevereiro e março de 2002.

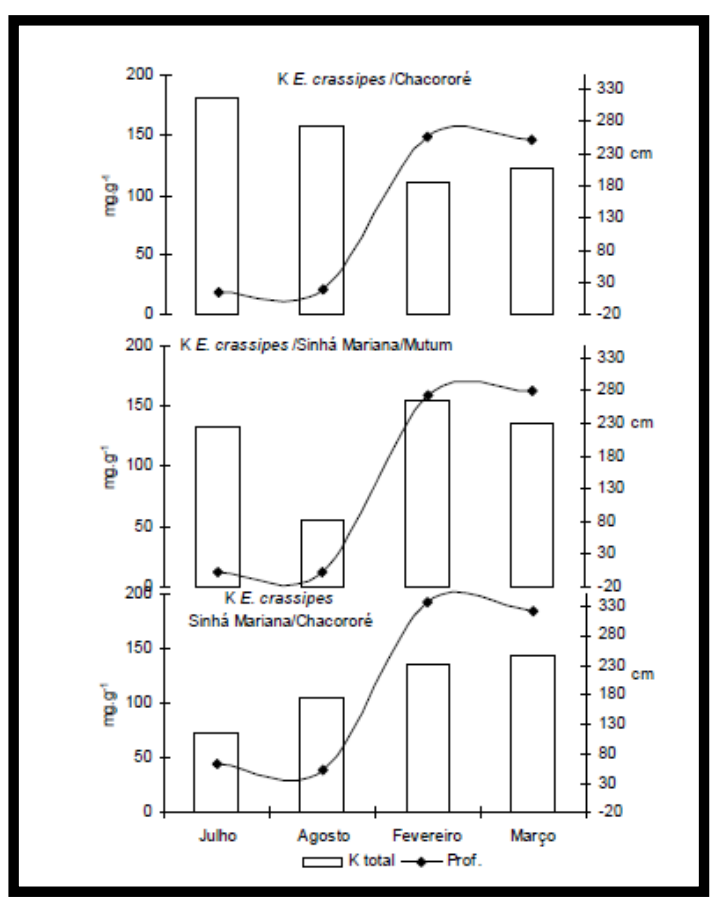

Fonte: Autores (2021).

As maiores concentrações de potássio nas estruturas de E. crassipes em Chacororé foram obtidas na estiagem sendo pecíolo com 45,49 mg.g-1 > limbo 39,02 mg.g-1 > rizoma mg.g-1 > estolão mg.g-1 > raiz 17,34 mg.g-1 > detrito 5,72 mg.g-1 $\mathrm{Na}$ cheia as concentrações foram estolão $35,93 \mathrm{mg} . \mathrm{g}-1$ > rizoma $23,57 \mathrm{mg} . \mathrm{g}-1$ > pecíolo 21,04 mg.g-1 > raiz 20,83 mg.g-1 > limbo 11,45 mg.g-1 > detrito 3,86 mg.g-1.

Em Sinhá Mariana/Mutum a concentração de potássio nas diferentes porções de E. crassipes não seguiram um padrão de distribuição segundo período hidrológico. As maiores concentrações obtidas durante a estiagem foram estolão 39,05mg.g-1 > limbo 17,08 mg.g-1 > pecíolo 16,92 mg.g-1 > detrito 12,76 mg.g-1 > raiz 5,31 mg.g-1 > rizoma 2,63 mg.g-1. na cheia as concentrações foram, estolão 42,21 mg.g-1 > rizoma 33,49 mg.g-1 > raiz 31,87 mg.g-1 > pecíolo 26,10 mg.g-1 > limbo 6,68 mg.g-1 > detrito 4,13mg.g-1 (Figura 15b).

Em Sinhá Mariana/Chacororé E. crassipes mostrou maiores concentrações de potássio no período de cheia exceto para detrito que apresentou maior concentração na estiagem. No entanto não houve diferença significativa quanto aos outros meses, as maiores concentrações durante a cheia foram de estolão $44,01 \mathrm{mg} . \mathrm{g}-1$ > pecíolo 31,80mg.g-1 > limbo 20,75 mg.g-1 > rizoma 19,56mg.g-1 > raiz 19,43mg.g-1 > detrito 4,61mg.g-1. Na estiagem os valores foram, estolão 32,02 mg.g-1 > pecíolo 24,45 mg.g-1 > limbo 12,66 mg.g-1 > rizoma 9,19 mg.g-1 > raiz 6,40 mg.g-1 > detrito 5,24 mg.g-1 (Figura 15c).

Quando as estruturas de E. crassipes foram avaliadas estatisticamente para verificar se haviam variações significativas espacial e temporal entre as concentrações de potássio, os resultados obtidos foram os seguintes, no limbo houve diferença significativa temporal (entre estiagem e cheia) sendo $\mathrm{N}=36, \mathrm{p}<0,05, \mathrm{r} 2=0,71$, houve também diferença significativa quando comparada tempo-espacialmente $\mathrm{N}=36, \mathrm{p}<0,01, \mathrm{r} 2=0,66$, sendo que não houve diferença espacial. Pecíolo apresentou diferença significativa tempo-espacial $\mathrm{N}=36, \mathrm{p}>0,01, \mathrm{r} 2=0,54$. Rizoma apresentou diferença estatística significativa temporal e tempo-espacial (quando comparada ao mesmo tempo espaço e tempo) $\mathrm{N}=36, \mathrm{p}<0,01, \mathrm{r} 2=0,68$ e $\mathrm{N}=36, \mathrm{p}<0,01, \mathrm{r} 2=0,63$ respectivamente. Raiz apresentou diferença temporal, $\mathrm{N}=36, \mathrm{p}<0,01, \mathrm{r} 2=0,74$. Estolão não apresentou diferença significativa 
tempo-espacial, temporal ou espacial. Detrito não apresentou diferença estatística significativa temporal, espacial ou tempoespacial.

Figura 15: Concentração de potássio (mg.g-1) na biomassa de E. crassipes no Sistema de baías Chacororé-Sinhá Mariana, durante a estiagem de 2001 e a cheia de 2002. Em Chacororé (a), Sinhá Mariana/Mutum (b), Sinha Mariana/ Chacororé (c) e K total (d) em E. crassipes.
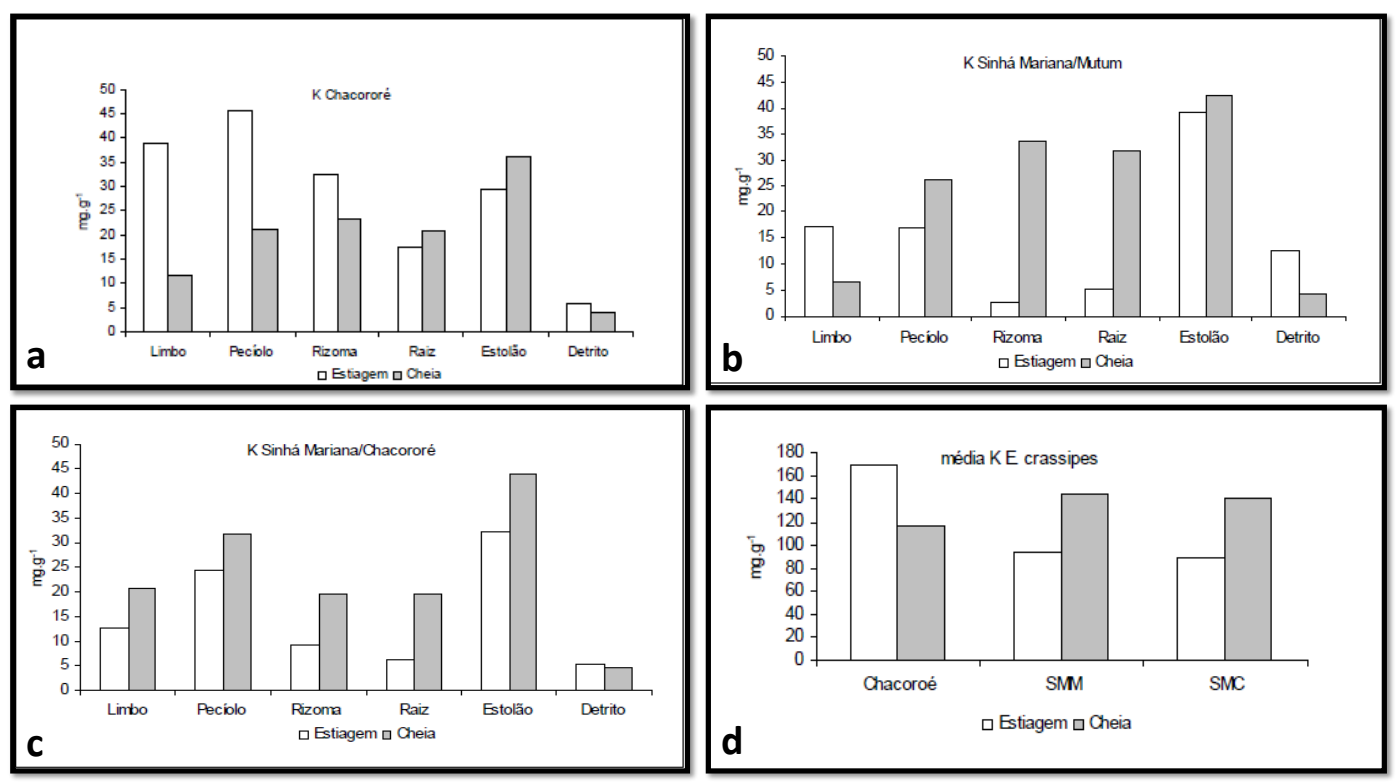

Fonte: Autores (2021).

As maiores concentrações de potássio em E. crassipes na estiagem foram obtidas em Chacororé 169,37mg.g-1 enquanto as plantas da estação Sinhá Mariana/Mutum apresentaram 93,75mg.g—1 e Sinhá Mariana/Chacororé 89,93mg.g-1. $\mathrm{Na}$ cheia as maiores concentrações observadas foram em Sinhá Mariana/Mutum 144,48mg.g-1 seguida de Sinhá Mariana/Chacororé 140,15mg.g-1 e Chacororé que foi a única estação de coleta a diminuir a concentração de potássio na biomassa da planta na cheia ficando com 116,62mg.g-1 (Figura 15d).

Potássio apresentou diferença estatística significativa tempo-espacial $\mathrm{N}=36, \mathrm{p}<0,01, \mathrm{r} 2=0,78$, não havendo diferença temporal ou espacial quando analisadas separadamente.

\section{Discussão}

A maior concentração de conteúdo mineral em E. crassipes no sistema de baías Chacororé-Sinhá Mariana foi obtido durante a estiagem em todas as estações de coleta. Abdo (1999), observou maior teor de conteúdo mineral tanto para esta mesma espécie como para Pistia stratiotes.

A raiz foi a estrutura da planta que acumulou maior concentração de conteúdo mineral, isto foi observado durante a estiagem. A mesma estrutura de E. crassipes acumulou maior concentração de conteúdo mineral nas pesquisas de Abdo (2004) embora tenha ocorrido durante a cheia, esta mesma autora observou nas raízes de Pistia stratiotes maior concentração de conteúdo mineral na estiagem. Da Silva (1990), também observarou maior concentração de conteúdo mineral na raiz de $E$. crassipes e Ludwigia natans na estiagem e no limbo de E. azurea.

No sistema de baías Chacororé-Sinhá Mariana a maior concentração de fósforo e nitrogênio na biomassa de $E$. crassipes foi observada na estiagem, enquanto que a biomassa total foi maior na cheia. Provavelmente esta é uma estratégia da 
planta que procura estocar nutrientes para o período de cheia quando serão necessários para aumentar a biomassa. Da Silva \& Esteves (1993) e Abdo (1999) observaram o mesmo padrão em outras baías no Pantanal.

Reddy et al (1989) e Reddy et al (1990) realizaram experimentos em tanques com E. crassipes sob diferentes concentrações de nitrogênio e fósforo na água perceberam que com o aumento da oferta desses elementos na água as plantas aumentavam em biomassa e na concentração destes nutrientes na mesma. Conforme aumentava a adição de nitrogênio e fósforo na água as plantas continuavam assimilando os nutrientes, mais deixavam de aumentar a biomassa.

Taheruzzaman e Kushari (1991) também observaram o aumento da biomassa de E. crassipes em área enriquecidas com serrapilheira e acréscimo de nitrato e ortofosfato, observaram ainda maior acúmulo nos tecidos da planta quando as condições ambientais não favoreciam o desenvolvimento da biomassa.

O mesmo padrão de comportamento foi observado em experimentos realizados por Petrucio \& Esteves (2000b) observando aumento da biomassa e concentração de nitrogênio e fósforo e mesmo quando a biomassa para de crescer ocorre aumento na concentração desses nutrientes na mesma.

Nesta pesquisa as maiores concentrações de nitrogênio e fósforo na água foram obtidas durante a estiagem quando $E$. crassipes estava apenas estocando nutrientes pois as oscilações na temperatura e a ação do vento não permitiam expansão, fazendo com esta permanecesse sempre nas margens das baías. Asaeda et al (2000) em experimento com Potamogetum pectinatus foi observado o mesmo comportamento que o observado neste estudo, que é o de absorver nutrientes na seca ou enchente para expandir na cheia.

Segundo Esteves (1998), em ecossistemas aquáticos densamente povoados por macrófitas aquáticas, a maior porção de nutrientes está estocada na biomassa das macrófitas aquáticas, isso pode ser observado neste estudo, pois todas os nutrientes apresentaram concentrações mais elevadas na biomassa de E. crassipes do que no compartimento água.

Estudos com E. crassipes realizados no Pantanal e em outras áreas, quando comparado a este estudo Abdo (2004), observou concentrações menores de nutrientes nesta espécie, Da Silva (1990) estudando duas baías no Pantanal também encontrou menores concentrações de nutrientes na biomassa desta espécie; Petrucio e Esteves (2000a e 2000b) também observaram no Estado de São Paulo valores inferiores ao deste estudo; Da Silva et al (1994) estudando o lago Recreio no Pantanal mediu nas estruturas de E. crassipes,.valores inferiores aos obtidos nesse trabalho.

E. crassipes tem sido citada por muitos autores como uma das espécies que mais acumula nutrientes em sua biomassa e por isso tem sido usada para recuperar áreas poluídas por diversos graus de poluição e pelos mais diversos tipos de poluentes (Boyd, 1970; Gosset \& Norris, 1971; Sato \& Kondo 1981; De Busk et al , 1983; Gutierrez et al, 1996 entre outros).

Em trabalhos comparativos de absorção de concentrações de nutrientes por E. crassipes e outras espécies de macrófitas aquáticas esta frequentemente tem acumulado maior quantidade de nutrientes e em quantidades muitas vezes menores que as observadas neste estudo. O maior acumulo de nutrientes na biomassa de $E$. crassipes quando comparada com Pistia stratiotes (Abdo, 1999), Ludwigia natans (Da Silva 1990), Hydrocotyle umbellata (Agami \& Reddy, 1991), Pistia stratiotes (Agami \& Reddy, 1990), Salvinia auriculata (Petrucio \& Esteves, 2000a e 2000b), Scirpus cubensis e E. azurea Nogueira et al (1996), Da Silva et al (1994) obteve valores inferiores para E. azurea, Pontederia lanceolata, eleocharis sp., Nymphaea amazonum e Thypha dominguensis.

Van Oorschot et alli (2000) trabalhando com diferentes mesocosmos de diferentes graus de umidades (seco, úmido e encharcado), percebeu que naqueles com maior quantidade de água, nitrogênio e fósforo eram liberados e absorvidos pelas plantas com mais facilidade. Este é um fator que pode ser extrapolado para este estudo pois com o aumento da coluna d'água e aumento de nutrientes não só a biomassa aumentou mais também a concentração nos nutrientes em E. crassipes.

A grande concentração de nutrientes observada na biomassa de E. crassipes contribui para entrada de nutrientes neste sistema de baías e certamente em todo o Pantanal. Além disso esta condição de armazenar nutrientes também contribui para 
acelerar a sucessão ecológica na área alagável devido a deposição da necromassa desta espécie neste período. Zimmer (2002), observou estudando o processo de decomposição de diferentes áreas alagáveis na Alemanha, que os diferentes graus de umidade, a biomassa e a diversidade de espécies vegetais e de decompositores, afetava a velocidade de liberação de nutrientes energia nas áreas alagáveis.

Segundo Murphy (2002) a biomassa, diversidade e abundância de espécies de macrófitas aquáticas estão diretamente relacionadas a fatores tais como, área do lago, altitude, estado trófico, condutividade e pH entre outros, são essas características que favorecem aumento ou diminuição da biomassa de uma espécie. No sistema de baías Chacororé-Sinhá Mariana $E$. crassipes foi dominante apenas durante a cheia, reduzindo a biomassa durante a estiagem, certamente influenciada por fatores como os acima citados e outros como, sucessão por espécies fixas no sedimento como E. azurea e outras.

Outro fato que vale a pena ser ressaltado é o de que mesmo nos pontos em que Sinhá Mariana/Mutum apresentou maiores valores de nutrientes na biomassa de E. crassipes, isto ocorreu apenas no mês de agosto quando esta comportava-se como um brejo, pois praticamente não apresentava coluna d'água na estação de coleta.

Conserva (1988), estudando populações de Paspalum fasciculatum, em dois ambientes da Várzea amazônica, observou valores médios de 8,5g.kg-1 e 9,3 g.kg-1 de nitrogênio no rio Solimões e lago Central respectivamente, sendo que apenas a baía Chacororé apresentou neste estudo concentrações mais elevadas que as observadas por esta autora.

A quantidade de fósforo observada pela autora (op. cit.) foi de 1,5 g.kg-1 e 1,4 g.kg-1 para os mesmos locais, neste estudo as estações Chacororé e Sinhá Mariana/Chacororé apresentaram valores inferiores a estes. Sinhá Mariana/Mutum apresentou valores mais elevados que os observados por Conserva (1998).

Potássio apresentou concentrações de 13,5 g.kg-1 e 11,1 g.kg-1 nas mesmas áreas sendo maiores que os observados em qualquer uma das estações deste estudo.

Cálcio apresentou valor de 6,6 g.kg-1 no rio Solimões e 6,6 g.kg-1 no lago Central, enquanto neste estudo os valores foram muito inferiores.

Magnésio apresentou valores de 2,7 g.kg-1 (rio Solimões), e 3,2 g.kg-1 (lago Central), neste estudo os valores foram maiores que os do rio Solimões e muito próximo dos valores do lago Central.

O sódio apresentou $0,7 \mathrm{~g} . \mathrm{kg}-1$ no rio Solimões e $0,7 \mathrm{~g} \cdot \mathrm{kg}-1$ no lago Central, sendo estes valores também muito próximos dos observados neste estudo para qualquer uma das estações de coleta.

$\mathrm{O}$ pulso de inundação exerce influência positiva na concentração de alguns nutrientes na biomassa de E. crassipes e exerce influência inversa fazendo com que alguns diminuam a concentração com o aumento do volume de água.

Outras macrófitas aquáticas tais como Paspalum repens e E. azurea tem controlado anualmente o desenvolvimento de E. crassipes na baía Chacororé e este papel tem sido desempenhado principalmente por E. azurea na baía Sinhá Mariana.

Foi verificado também que no sistema de baías Chacororé-Sinhá Mariana a diferença espacial é significativa, e que as diferentes origens da água que inunda estas baías, exerce importante influência no metabolismo das mesmas.

Dessa forma quando analisadas as concentrações de nutrientes na biomassa de E. crassipes, temporalmente e espacialmente, segundo nosso modelo preditivo, Chacororé > Sinhá Mariana/Chacororé > Sinhá Mariana/Mutum, observamos que este foi corroborado para as seguintes variáveis: condutividade, turbidez, temperatura do ar e da água, íon amônio, nitrato, potássio, cálcio, magnésio e sódio na água, em E. crassipes potássio, nitrogênio, cálcio, magnésio e biomassa lembrando que os bancos de E. crassipes foram na cheia muito maiores na baía Chacororé que em qualquer outra estação de coleta.

A produção de biomassa e nutrientes em E. crassipes na baía Chacororé pode ser considerada elevada durante a cheia, principalmente quando comparada a Sinhá Mariana e a muitas outras baías do Pantanal anteriormente estudadas por outros autores. 
Dessa forma, verificou-se que o pulso de inundação desenvolve influência importante no aumento do nutrient da biomassa de E. crassipes no sistema de Baías Chacororé-Sinhá Mariana, aliado ainda à alta temperatura observada no campo e ao nutriente na água. Outro fator importante é que o sistema de baías exporta nutrientes para outras regiões do Pantanal atra vés dos "corixos" que ligam o sistema aos rios da região. Chacororé foi o ponto amostral que apresentou maior concentração de nutrientes na biomassa nas áreas estudadas.

\section{Conclusão}

Através desses resultados podemos ver que Chacororé passou de menos produtiva durante a estiagem para ser de longe a mais produtiva na cheia. Este fator esta ligado a maior concentração de nutrientes dissolvidos na água desta baía.

A concentração de nutrientes na biomassa de $E$. crassipes foi maior na cheia para nitrogênio e magnésio e na estiagem para fósforo, sódio e conteúdo mineral, o pulso de inundação exerceu influencia com o aumento do volume de água.

Foi verificado também que no sistema de baías Chacororé-Sinhá Mariana a diferença espacial é significativa, e que as diferentes origens da água que inunda estas baías, exerce importante influencia no metabolismo das mesmas.

A produção de biomassa e nutrientes em E. crassipes na baía Chacororé pode ser considerada elevada durante a cheia, principalmente quando comparada a Sinhá Mariana e a muitas outras baías do Pantanal anteriormente estudadas por outros autores.

Em função das mudanças climáticas e mudanças no ciclo hidrológico a que está sujeita essa região, cabe expressar a necessidade de repetição desse estudo para a mesma espécie e ainda para outras espécies também abundantes no Sistema de Baía chacororé-Sinhá Mariana

\section{Agradecimentos}

Ao Projeto de Ecologia do Pantanal (IB-UFMT/MPIL, Plön) apoiado pelo SHIFT (Programa CNPq-IBAMA-DLR0, Cooperação Bilateral Científica Técnica Brasil-Alemanha pelo apoio logístico nesta pesquisa. Ao CNPq para concessão de bolsa de mestrado para o primeiro autor. À FAPEMAT, pelo apoio logístico para a realização desta pesquisa e ainda para o Programa de Pós-Graduação em Ecologia e Conservação da Biodiversidade pela Universidade Federal de Mato Grosso).

\section{Referências}

Abdo, M. A. A. (1999). Biomassa, composição química e estoque de nutrientes em Eichhornia crassipes e Pistia stratiotes, na baía do Ninhal Corutuba. Município de Barão de Melgaço, Pantanal Mato Grossense. Dissertação de mestrado. Universidade Federal de Mato Grosso, Instituto de Biociências, Cuiabá, Brazil, 72f.

Abdo, M. S. A. \& Da Silva, C. J. (2004). Limnological characteristics of water bodies of the Corutuba Nesting Site in Brazil's Pantanal, Acta Limnological Brasiliensia, 4(16),359-368.

Abdo, M., Da Silva, C. J. \& Nunes, J. R. S. (2012). Diversidade de Macrófitas Aquáticas do sistema de baías Chacororé-Sinhá Mariana. IN: Água, Biodiversidade e Cultura do Pantanal, Estudos ecológicos e etnoecológicos no sistema de baías Chacororé-Sinhá Mariana, Org. Da Silva, C. J. \& Simoni, J. $272 \mathrm{p}$.

Adamoli, J. (1982). O Pantanal e suas relações fitogeográficas com os cerrados. Discussão sobre o conceito de "Complexo do Pantanal", In: Anais do XXXII Congresso Nacional de Botânica, Teresina PI, 109-119p.

Allen, S. E. (1989). Chemical Analysis of Ecological Materials. Second Edition. Blackwell Scientific Publications, London, 368p.

Amaral Filho, Z. P. (1986). Solos do Pantanal Mato-grossense. In: Simpósio sobre Recursos Naturais e Socioeconômicos do Pantanal. Corumbá, MS. p.91104.

Anderson, J. M. \& Ingram, J. S. I. (1996). Tropical Soil Biology and Fertility - A Handbook of methods. Second Edition., Information Press, Eynsham-UKCab International. $221 \mathrm{p}$.

Asaeda, T., Trung V. K. \& Manatunge J. (2001). Modeling the effect of macrophyte growth and decomposition on the nutrient budget in shallow lakes, Aquatic botany, 68, 217-237. 
Boyd, C.E. (1970). The limnological role of aquatic macrophytes and their relationship to reservoir management, In: Reservoir fisheries and limnology, Ed. Hall G. E. (American Fish Society of Special Publishers.

Brown-Jr. K. S. (1986). Zoogeografia da região do Pantanal Mato-grossense. In: Simpósio sobre Recursos Naturais e Socioeconômicos do Pantanal. Corumbá, MS. p.137-178.

Carmouze, J. P. (1994). O metabolismo dos Ecossistemas Aquáticos: Fundamentos teóricos, métodos de estudos e análises químicas. São Paulo. Ed. Edgard Blücher. FAPESP. 253f.

Conserva, A. S. (1998). Biomassa, ciclo de vida e composição química de duas populações de Paspalum fasciculatum Willd. Ex, Fluegge (Poaceae) em diferentes habitats de Várzea da Amazônia Central, Dissertação de mestrado. Universidade do Amazonas, Instituto Nacional de Pesquisas da Amazônia, Manaus, Brazil, 90f.

Da Silva, C. J. \& Esteves, F. A. (1993). Biomass of three macrophytes in the Pantanal of the Mato grosso, Brazil Int. J. Ecol. Environ. Sci. 19: 11-23.

Da Silva, C. J. \& Figueiredo, D. M. (1999). Variação limnológica das baías de Chacororé e de Sinhá Mariana, Pantanal Mato-grossense, Mato Grosso (MT), Revista Mato-Grossense de Geografia, Ano, 03/04, nº3/04, p.57-75.

Da Silva, C. J. (1990). Influência da variação do nível d'água sobre a estrutura e funcionamento de uma área alagável do Pantanal Matogrossense (Pantanal de Barão de Melgaço) - MT. São Carlos, SP. (Tese de doutoramento) UFScar, Universidade Federal de São Carlos. 250f.

Da Silva, C. J., Sousa, K. N. S., Ikeda-Castrillon, S. K., Lopes, C. R. A. S., Nunes, J. R. S., Carniello, M. C., Mariotti, P. R., Lazaro, W. L., Morini, A., Zago, B. W., Façanha, C. L., Albernaz-Silveira, R., Loureiro, E., Viana, I. G., Oliveira, R. F., Cruz, W. J. A., Arruda, J. C., Sander, N. L., Freitas-Junior, D. S., Pinto, V. R., Lima, A. C. \& Jongman, R. H. G. (2015). Biodiversity and its drivers and pressures of change in the wetlands of the Upper Paraguay-Guaporé Ecotone, Mato Grosso (Brazil). Land Use Policy 47: 163-178. https://doi.org/10.1016/j.landusepol.2015.04.004

Da Silva, C. J., Nunes, J. R. S. \& Simoni, J. (2012). O sistema de baías Chacororé-Sinhá Mariana. IN: Água, Biodiversidade e Cultura do Pantanal, Estudos ecológicos e etnoecológicos no sistema de baías Chacororé-Sinhá Mariana, Org. Da Silva, C. J. \& Simoni, J. 272p.

Da Silva, C. J., Nogueira, F. \& Esteves, F. A. (1994). Composição química das principais espécies de macrófitas aquáticas do lago Recreio, Pantanal Matogrossense (MT), Revista Brasileira da Biologia, 54 (4): 617-622.

De Busk, T. A., Williams, L. D. \& Ryther, J. H. (1983). Removal of nitrogen and phosphorous of waste water in a waterhyacinth based treatment system, Journal of Environment Quality, vol. 12, nº2.

Esteves, F. A. (1998). Fundamentos de Limnologia, (2a ed.), Ed. Interciência, 602p.

Furch, K. \& Junk, W. J. (1997). The chemical composition, food value, and decomposition of herbaceous plants, leaves and leaf litter of floodplain forests, In: The central Amazon floodplain, Ecology of a pulsing system, Editor, W.J. Junk, SPRINGER, 187-205pp, 525p.

Golterman, H. L., Clymo, R. S. \& Ohnstad, M.A. (1978). Methods for physical and chemical analysis of fresh waters. 2nd ed. IBP Handbook, n0 8. Blackwell Scientific publications, Oxford. Edinburgh London Melbourne. 214 p

Gopal, B. (1987). Water hyacinth, Aquatic Plant Study, Elsevier, Amsterdam, Oxford, New York and Tokyo, 471p.

Gossett, D. R. \& Norris Jr, W. E. (1971). Relationship between nutrient availability and content of nitrogen and phosphorous in tissues of the aquatic macrophyte, E. crassipes (Mart.) Solms, Hydrobiologia, vol. 38, 15-28.

Gutiérrez, E., Huerto, R., Saldaña, P. \& Arreguin F. (1996). Strategies for waterhyacinth (Eichhornia crassipes) control in the México, Hydrobiologia, 340: 181-185.

Hamilton, S. K., Sippel S. J., Calheiros, D. F. \& Melack, J. M. (1996). Chemical characteristics of surface waters of the southern Pantanal. In II Simpósio sobre Recursos Naturais e Socioeconômicos do Pantanal. Corumbá, MS. p. $89-100$.

Howard-Williams, C. (1979). Distribution, biomass and role of aquatic macrophytes in Lake Sibaya, In: Lake Sibaya, Editor: B.R., Allanson, Dr. W. Junk, bv, Publishers The Hague - Boston - London.

Mackereth, F. J. H., Heron, J. \& Talling, J.F. (1978). Water Analysis: Some revised methods for limnologists. Cumbria, Freshwater Biological Association. 120p. (Scientific Publication $\mathrm{n}^{\circ} 36$ ).

Murphy, K. J. (2002). plant community and plant diversity in soft water lakes in northern Europe. Aquatic botany, 73, 287-324.

Nogueira, F. M. B. (1989). Importância da macrófitas aquáticas Eichhornia azurea Kunth e Scirpus cubencis Poepp \& Kunth na ciclagem de nutrientes e nas principais variáveis limnológicas da Lagoa do Infernão. 147f. Dissertação. UFSCar, São Carlos.

Nogueira, F.M.B, Esteves, F.A. \& Prast, A.E. (1996). Nitrogen and phosphorous concentration of different structures of the aquatic macrophytes Eichhornia azurea Kunth and Scirpus cubensis Poepp \& Kunth in relation to water level in Lagoa Infernão (São Paulo, Brazil), Hydrobiologia, 328:199-205.

Nunes, J. R. S. \& Da Silva C. J. (2009). Concentração de íons no sistema de baías Chacororé-Sinhá Mariana, Pantanal de Mato Grosso Uniciências.

Nunes, J. R. S. \& Da Silva, C.J. (2005). variáveis limnológicas sob estandes de Eichhornia crassipes (Mart) Solms, no Sistema de baías Chacororé-Sinha Mariana, Pantanal de Mato Grosso. Uniciências.

Nunes, J. R. S., Da Silva, C. J. \& Ferraz, L. (2017). Mato Grosso e seus biomas: Biodiversidade, Desafios Sócio Ambientais, Unidades de Conservação Iniciativas de Políticas Públicas e Privadas para a Conservação, Revista Gestão Universitária Vol. 07. 
Nunes, J. R. S., Da Silva, C. J. (2021). Biomass of Eichhornia crassipes, (Mart) Solms. In the Chacororé-Sinhá Mariana, lake System Pantanal of Mato Grosso, Brazil, Research, Society and Development, 10(2)

Nunes, J. R. S., Da Silva, C. J., Ikeda-Castrillon, S. K. \& Sander, N. L. (2020). Mudança na composição de assembleia de aves aquáticas associadas com mudanças no nível de água em uma Zona de Transição Terrestre Aquática no Pantanal de Mato Grosso, Brasil. Research, Society and Development, 9(10), e4479108555. https://doi.org/10.33448/rsd-v9i10.8555

Nunes, J. R. S., Loverde S., Pinto-Silva V., Ferraz L., Amorim A., Costa C. P., Mondim L. A., Silveira J. S., Favalessa O., Gonçalez C. H., Troy W. P. \& Urquiza N. G. (2006). Variação diária das características limnologicas da baía dos coqueiros, Pantanal de Poconé - MT, UNICiências, vol.10, 31-46p.

Nunes, J. R. S., Da Silva, C. J. \& Abdo, M. (2012). As águas do Sistema de Baías Chacororé-Sinhá Mariana. IN: Água, Biodiversidade e Cultura do Pantanal, Estudos ecológicos e etnoecológicos no sistema de baías Chacororé-Sinhá Mariana, Org. Da Silva, C. J. \& Simoni, J. 272p.

Nunes, J. R. S., Da Silva, C. J. \& Albernaz-Silveira, R. (2012). Avifauna do Rio Cuiabá e do Sistema de Baías Chacororé-Sinhá Mariana. IN: Água, Biodiversidade e Cultura do Pantanal, Estudos ecológicos e etnoecológicos no sistema de baías Chacororé-Sinhá Mariana, Org. Da Silva, C. J. \& Simoni, J. $272 \mathrm{p}$

Panosso, R. F. (1993). Influência do regime hidrológico e das características morfométricas sobre algumas variáveis limnológicas de um lago amazônico (Lago Batata, PA) impactado por rejeito de bauxita, 116f. Dissertação, UFRJ, Rio de Janeiro.

Petrucio, M. M. \& Esteves, F. A. (2000a). Influence of photoperiod on the uptake of nitrogen and phosphorous in the water by Eichhornia crassipes and Salvinia auriculata, Revista Brasileira de Biologia, 60(30): 373-379.

Petrucio, M. M. \& Esteves, F. A. (2000b). Uptake rates of nitrogen and phosphorous in the water by Eichhornia crassipes and Salvinia auriculata, Revista Brasileira de Biologia, 60(2): 229-236.

Pinto-Silva, V. (1980). Variações Diurnas de Fatores Ecológicos em Quatro Lagoas Naturais do "Pantanal Mato-grossense" e seu estudo comparativo com dois lagos da Amazônia Central e um lago Artificial (Represa do Lobo, "Broa”, São Carlos, SP. (dissertação). UFScar - Universidade Federal de São Carlos, departamento de Ciências Biológicas. 281f).

Ramachandra, T. V., Ahalya, N., Bhagat, A. K., Desai, S. R., Diwakar, K. M., Hrishikash, M., Lakshminarayana, H., Mahesh, B., Payne, M., Ajay, N., Kneisel, N., Julka, P., Mohanta, P. K., Jha, R. K., Rajink, A. R., Rao, G. R., Samer, A., Sanjeeva, N. K., Sanjeeva, N., Sathiskumar, R., Somnath, H., Sreekantha, U., Sudhira, H. S. \& Mukri, V. (2002). Limnology, Energy and wetland research groups (www. limgis.com.br).

Reddy, K. R., Agami, M., Tucker, J. C. (1989). Incluence of nitrogenious on growth and nutrient storage by water hyacinth (E. crassipes, Mart.) Solms) plants, Aquatic botany, 37,355-365.

Reddy, K. R., Agami, M., Tucker, J. C. (1990). Incluence of phosphorous on growth and nutrient storage by water hyacinth (E. crassipes, Mart.) Solms) plants, Aquatic botany, 37,355-365.

Riemer, D. N. (1984). Introduction to freshwater vegetation, AVI, 207p.

Santos, S. B. S. dos, Oliveira, Y. R., Silva, P. H. da \& Abreu, M. C. de. (2017). Percepções dos moradores acerca de Typha angustifolia subsp. Domingensis (Pers.) Rohrb. (Typhaceae Juss.) em áreas alagadiças de Picos-PI, Nordeste do Brasil. Research, Society and Development, 4(3), 184-198. https://doi.org/10.17648/rsd-v4i3.68

Sato, H \& Kondo, T. (1981). Biomass prodetion of waterhyacinth and its hability to remove inorganic minerals from water, I effect of the concentration of culture solutions on the rates of plant growth and nutrient uptake, Japanese joural of ecology, 31: 257-267.

Silva, T. C. (1986). Contribuição da geomorfologia para o conhecimento e valorização do Pantanal. In: Simpósio sobre Recursos Naturais e Socioeconômicos do Pantanal. Corumbá, MS. p.77-90.

Taheruzzaman, Q. \& Kushari, D. P. (1991). Influence of leaf leachate-enriched water of neem (Azadirachta indica A. Juss.) and shirish (Albizzia lebbek Benth.) in the growth of Eichhornia crassipes (Mart.) Solms, Aquatic Botany, 40, 1-9, Elsevier Publishers B.V., Amsterdam.

Van Oorschot, M., Van Gaalen, N., Maltby, E., Mockler, N., Spink, A. \& Verhoeven, J.T.A. (2000). Experimental manipulation of water level in two French riverine grassland soil, Acta Oecologica, 21 (1), 49-62.

Zimmer, M. (2002). Is decomposition of wetland leaf litter influenced by its species richness? Soil biology and biochemistry, 34, $277-284$. 